Portland State University

PDXScholar

\title{
Attitudes toward Science (ATS): An Examination of Scientists' and Native Americans' Cultural Values and ATS and their Effect on Action Priorities
}

Adam T. Murry

Portland State University

Follow this and additional works at: https://pdxscholar.library.pdx.edu/open_access_etds

Part of the Indigenous Studies Commons, Industrial and Organizational Psychology Commons, Philosophy of Science Commons, and the Race and Ethnicity Commons Let us know how access to this document benefits you.

\section{Recommended Citation}

Murry, Adam T., "Attitudes toward Science (ATS): An Examination of Scientists' and Native Americans' Cultural Values and ATS and their Effect on Action Priorities" (2013). Dissertations and Theses. Paper 674.

https://doi.org/10.15760/etd.674

This Thesis is brought to you for free and open access. It has been accepted for inclusion in Dissertations and Theses by an authorized administrator of PDXScholar. Please contact us if we can make this document more accessible: pdxscholar@pdx.edu. 
Attitudes toward Science (ATS): An Examination of Scientists' and Native Americans' Cultural Values and ATS and Their Effect on Action Priorities

by

Adam T. Murry

A thesis submitted in partial fulfillment of the requirements for the degree of

\author{
Master of Science \\ in \\ Psychology
}

Thesis Committee:

Keith James, Chair

David Morgan

Thomas Kindermann

Portland State University

2013 
(C) 2013 Adam T. Murry 


\begin{abstract}
Science has been identified as a crucial element in the competitiveness and sustainability of America in the global economy. American citizens, especially minority populations, however, are not pursuing science education or careers. Past research has implicated 'attitudes toward science' as an important factor in the public's participation in science. I applied Ajzen's (1991) Theory of Planned Behavior to attitudes toward science to predict science-related sustainability-action intentions and evaluated whether scientists and Native Americans differed in their general attitudes toward science, cultural values, and specific beliefs about science. Analyses revealed that positive attitude toward science and the cultural value of individualism predicted intentions to engage with science-related sustainability actions. Unexpectedly, scientists and Native Americans did not differ in their cultural values or positive attitude toward science. However, Natives Americans held significantly more negative attitude toward science than scientists. Implications for science education and attitudes towards science theory and application are discussed.
\end{abstract}




\section{ACKNOWLEDGEMENTS}

I would like to formally acknowledge the participants of the Pacific Northwest Native Community Sustainability Project's (PNNACSP) Indigenous Sustainability Workshops who supplied their input that we might share in knowledge. I also want to thank my friends and family who offered their support throughout my education and my adviser, Keith James, who provided me with access to the road I need to walk to get where I need to go. Thank you.

This project was made possible with funding from the National Science Foundation (\#NSF0646807) to Dr. Keith James. 
Table of Contents $\quad$ PAGE

$\begin{array}{lll}\text { Abstract } & \mathrm{i}\end{array}$

$\begin{array}{ll}\text { Acknowledgements } & \text { ii }\end{array}$

List of Tables $\quad$ vi

List of Figures $\quad$ vii

Overview: Science, Technology, Attitudes, and Ethnic Minorities 1

Science and Technology in Today's World 2

The Problem of Scientific Illiteracy $\quad 4$

$\begin{array}{ll}\text { The Problem of Underrepresentation } & 6\end{array}$

$\begin{array}{lr}\text { Attitudes Implicated } & 8\end{array}$

Attitudes, Culture, and Science $\quad 10$

The Theory of Reasoned Action and the Theory of Planned Behavior 10

$\begin{array}{ll}\text { Attitudes toward Science (ATS): A historical overview } & 12\end{array}$

Contemporary Research on Attitudes toward Science (ATS) 15

Culture and Inter-Group Effects on Attitudes toward Science 19

$\begin{array}{ll}\text { Science "Culture" } & 21\end{array}$

Native American Culture and Science $\quad 23$

$\begin{array}{ll}\text { Native culture values } & 24\end{array}$

$\begin{array}{ll}\text { Exposure to science and technology } & 26\end{array}$

$\begin{array}{ll}\text { Sustainability } & 28\end{array}$

Research Questions and Hypotheses $\quad 31$

Methods 35

$\begin{array}{ll}\text { Participants } & 35\end{array}$

$\begin{array}{ll}\text { Procedure } & 37\end{array}$ 
$\begin{array}{ll}\text { Measures } & 37\end{array}$

$\begin{array}{ll}\text { Beliefs about science } & 38\end{array}$

$\begin{array}{ll}\text { Cultural values } & 40\end{array}$

$\begin{array}{ll}\text { Sustainable intentions } & 41\end{array}$

$\begin{array}{ll}\text { Analyses } & 42\end{array}$

Results 44

Preliminary Reliability, Descriptive, and Correlation Analyses $\quad 44$

$\begin{array}{ll}\text { Attitudes toward science (ATS) } & 45\end{array}$

$\begin{array}{ll}\text { Cultural values } & 47\end{array}$

$\begin{array}{ll}\text { Sustainable action priorities } & 48\end{array}$

$\begin{array}{ll}\text { Beliefs about science } & 48\end{array}$

Hypothesis Testing

Attitudes toward Science (ATS) and the Theory of Planned Behavior (TPB) 53

General positive Attitudes toward Science (pATS) and negative Attitudes $\quad 55$ toward Science (nATS)

$\begin{array}{lr}\text { Cultural values } & 56\end{array}$

$\begin{array}{ll}\text { Beliefs about science } & 57\end{array}$

Discussion $\quad 61$

$\begin{array}{ll}\text { ATS on sustainable action intentions } & 62\end{array}$

$\begin{array}{ll}\text { ATS } & 63\end{array}$

$\begin{array}{ll}\text { Cultural values } & 64\end{array}$

$\begin{array}{ll}\text { Beliefs about science } & 65\end{array}$

$\begin{array}{ll}\text { Implications } & 68\end{array}$ 
ATS

Underrepresentation

Applications

73

Limitations/future directions

78

Conclusion

86

References

Appendix A: Morgan's Alternative Regression

108

Appendix B: Survey Instruments 
List of Tables

Table 1: Summary overview of supported hypotheses 52

Table 2: Full model summary of hierarchical regression 54 

attitudes on Intentions applied to attitudes toward science (ATS) on intentions to collaborate to equip Natives with science skills

Figure 2: The "deficit model" of attitudes toward science (ATS) 


\section{Overview:}

\section{Science, Technology, Attitudes, and Ethnic Minorities}

Science and technology have become a foundation for our way of life. In addition to the vast technologies that support our every activity, scientific skills and information guide the development of our society, nationally and globally, in terms of economy, environment, and health and human services. A society with such dependence on science and technology only stands to benefit from having a population that is well-versed in scientific methods and process. Unfortunately, the U.S. public has generally not embraced scientific knowledge, education or careers, particularly its ethnic subpopulations. To understand this aversion to science-based knowledge and careers, attitudes toward science has been targeted as an important area of research (Osborne, Simon, \& Collins, 2003).

In this project I advance research on attitudes toward science (ATS) by 1) examining ATS within Ajzen's (1991) Theory of Planned Behavior (TPB) model, and 2) identifying an antecedent to ATS based on in-group experiences with technology and science. This study also contributes to current literature on Native American science education and sustainability science. The background for this research is described along with what is currently known about attitudes toward science. I discuss the application of Ajzen's (1991) model to ATS and justify the comparison of science and Native cultural groups' cultural values, beliefs about science and technology, and attitudes toward science. My hypotheses are followed by the Methods and Results of my analyses. Implications of the results for theory, research, and practice follow in the Discussion. 


\section{Science and Technology in Today's World}

The significance of science and technology varies depending on whether we are considering the international or national context. At the level of the United States, science and technology are described as the medium through which our nation competes within the global community. In a warning presented to the President and Congress as early as 1989, a Task Force on Women, Minorities, and the Handicapped in Science and Technology stated, "America faces a shortfall of scientists and engineers by the year $2000 \ldots[w]$ ithout this kind of world-class science and technical excellence, America's competitive prospects dim" (Task Force, 1989, p. 2). Now, over twenty years later, the situation remains the same. Multiple authors have voiced the need for increasing science education and skills in the United States. For instance, in a CRS report to Congress, Matthews (2007, p. ii) writes, “An important aspect of U.S. efforts to maintain and improve economic competitiveness is the existence of a capable scientific and technological workforce." Similarly, in an address to Congress, Augustine (2007a, p. 2) concluded that "America's ability to compete in the years ahead will heavily depend upon its ability to maintain a strong position in the fields of science and engineering."

Within the nation, science and technological knowledge has also been targeted as critical to civic participation (Miller, 1983, 2004; Shen 1975). It has been argued that since our nation's reliance on scientifically-derived evidence is increasingly becoming part of our judicial and legislative processes, democratic participation in legal and political processes requires some acquaintance with the scientific process. As Shen 
(1975, p.266) noted, "It is not sufficient to leave all public decisions to technical experts, if for no other reason than that experts are not popularly elected."

For individuals, science and technological knowledge also provide an economic advantage. For instance, in the Bureau of Labor Statistic's 2020 projections by occupational category, almost half of the occupations earning over the annual median wage are in science and technology fields (see Sommers \& Franklin, 2012). Similarly, of the projected thirty fastest growing occupations for 2018, fifteen include science or math (BLS, 2009) ${ }^{1}$. Couple this with the fact that higher levels of education of any sort have been shown to relate to higher earnings and better employment (BLS, 2010) and matching one's occupational training with booming science and technology industries simply becomes wise practice.

The need and benefit of training in science is not solely monetary. Increased proficiency in science and technology fields ties into other (personal, national, and international) priorities such as the challenge of sustainable living. For instance, U.S. federal legislation, such as the Recovery Act, has made it a goal to develop “clean" technologies to reduce our dependence on foreign oil and create new markets to produce environmentally-friendly options (Fact Sheet, 2010; The Global Compact, 2009). For such options to take root at the individual level, citizens would need to be motivated to invest in "greener" products - sometimes with the understanding that they will have to pay higher prices and make other lifestyle changes (Griskevicius, Tybur \& Van de Bergh,

\footnotetext{
${ }^{1}$ See codes 15-000 through 29-000 of the Standard Occupational Classification system at http://www.bls.gov/soc/2000/soc_majo.htm
} 
2010). This requires willingness and ability to process the research-based information necessary to make sustainably-minded decisions given one also has sufficient means.

Accordingly, the World's Scientific Academies (2000) concluded, “A centerpiece of any strategy to achieve sustainability must be the accelerated development of (individual and national) capacities in science [and] engineering” (section 2.A, parentheses added). Actions taken by the government to promote science, technology, engineering, and math [STEM] education, knowledge-use, and careers have been diverse but, to this point, largely ineffective (Augustine, 2007; Kuenzi, 2008).

\section{The Problem of Scientific Illiteracy}

In general, the U.S. population knows very little about either scientific findings or the scientific method. For instance, since the 1980's, Miller has been conducting nationally representative surveys in the United States on the public's knowledge of basic scientific discoveries (i.e., twelve facts covered in textbooks used in the typical K-12 curriculum; Miller, 1983; 1998; 2004; Pardo \& Calvo, 2004). Miller (2004) reports that very few U.S. citizens can provide minimally acceptable definitions of a molecule (13\%), radiation $(10 \%)$, or how the internet functions $(16 \%)$; about a quarter understand that antibiotics do not kill viruses $(26 \%)$ or the function of computer software (28\%); and only a little more than half can correctly label the Sun as a star or describe the Earth's rotation around the Sun each year (20\% say the Sun rotates around the Earth). Finally, only about one-fifth of respondents could provide an explanation of what it meant to study something "scientifically" and less than one-third understood the purpose of an experiment. 
It is difficult in this context to believe that the average U.S. citizen would be able to comprehend the arguments for or against a particular new medicine, environmental policy, or technology -- at least not on the basis of scientific information. For the majority, views about science policies and technological innovations are not based on scientific reasoning. Therefore, organizations, political figures, lobbyists, and rights activists tend to appeal to things other than scientific evidence. In addition, they often try to heighten confusion about science information that works against their goals, such as in the case of the campaign by Big Tobacco to instill doubt in the research on the effects of smoking (Stocking \& Holstein, 2009).

A similar situation has been observed relative to U.S. science education. For instance, students in the U.S. perform worse than their international counterparts per grade, U.S. science teacher qualifications tend to be comparatively low, and the U.S. science curriculum has been deemed inadequate and in need of strengthening and other reform (Kuenzi, 2008; Matthews, 2007; U.S. Department of Education, 2006). According to the Program for International Student Assessment (PISA) in 2003, out of twenty-nine industrialized nations, students in the United States ranked 19th science literacy and 24th in math literacy (Lemke et al, 2004).

Once out of high school, fewer American students go into science, technology, engineering, and math (STEM) fields in college than in many other nations (e.g. 37\% compared to $59 \%$ in China or $66 \%$ in Japan) and of those who do as many as $50 \%$ switch majors in their first year (Augustine, 2005; Fleming, Engerman \& Williams, 2006). This has left a hole in graduate STEM education that international students have been quick to 
fill (Augustine, 2005). In 2009, international students took $44 \%$ of the doctorates earned at U.S. universities in the physical sciences, $46 \%$ of the math graduate degrees, and 55\% of those in engineering (NSF, 2009). Since it has become more difficult—and less attractive, given economic advances in other countries—-for foreign students to remain in the U.S. on completing their degrees, the limited numbers of U.S. students entering STEM fields threatens the ability of the U.S. to maintain its scientific and technological advantage (Matthews, 2007; NSF, 2009).

\section{The Problem of Underrepresentation}

A possible explanation for the drop in science education is America's changing demographics. The demographic group that supplied science and technology students in the past (i.e. White males) is decreasing in its percentage of the total U.S. population. American minorities (Black, Hispanic, and Native American/Alaskan Native) are considered underrepresented groups because their percentages in higher education, general, and science disciplines, in particular, are lower than their percentage of the population (NSF, 2011). Yet minority groups are predicted to comprise 50\% of the US population by 2050 (NSF, 2011). In a recent study, Lewis, Menzies, Najera and Page (2009) calculated the difference in ratio of White, Black, Latino, Asian, and Native Americans in biology ${ }^{2}$ to their percentage in the U.S. population. They found that when population ratios were taken into account, the percentages of Blacks, Latinos, and Native Americans in biology were significantly lower than their percentage in the population. In contrast, the percentage of Whites in biology was either equal or overrepresented to their

\footnotetext{
${ }^{2}$ Biological sciences are supposed to have made the greatest advances in minority recruitment (Lewis, Menzies, Najera \& Page, 2009, p. 962)
} 
percentage of the population. Asian/Pacific Islanders (a category unfortunately lumped together to combine national data sets across several years) were also overrepresented. Underrepresentation of ethnic minorities in STEM has been attributed to a variety of things: disparate science classroom-to-home cultures (Lemke, 2001); monocultural curriculum and teaching methods (Pan, 2006); assessment methods favoring Western science traditions (Lee, 1999); and the rising costs of STEM education (Fleming, Engerman \& Williams, 2006; Seymour, 2000). The government has recently funded a variety of programs targeted at facilitating STEM education for underrepresented groups. For instance, in a list of 207 Federal STEM educational programs, 19\% were explicitly geared toward education/career development of underrepresented groups, namely, minorities, women and persons with disabilities (GAO, 2005). The effectiveness of such programs has been limited, though. Congruent with the data on minority underrepresentation in STEM fields cited above, studies using nationally representative data have demonstrated that efforts to recruit minorities in STEM has boosted enrollment without affecting graduation rates (Seymour, 2000).

For Native Americans in particular, underrepresentation in STEM careers has implications at the local and global level. James and colleagues (e.g., 2000; 2006; James, Hiza, \& Doppelt, 2008; Murry, James, \& Drown, in press) have argued that the comparatively extreme problems faced by Native American individuals and communities (e.g., chronically high levels of unemployment; lower life expectancies; above-average levels of pollution of the physical environment) indicate a particular need for science and technological knowledge, skill, and education. Murry et al. (in press), along with others 
such as Cajete (1999; 2000), Cristancho and Vining (2004), Johnson and Murton (2007), Garroutte (1999), and even the United Nations (1992), have also made the case that Native American culture and traditional ecological knowledge (TEK) has much to offer science in general and sustainability science in particular. Thus, Native Americans will be the focus of the current work.

\section{Attitudes Implicated}

Beyond curricular and financial obstacles, participation in science activities and processing scientific information requires the motivation to do so. According to attitudinal theory, such motivation would be the direct result of a person's attitude. Within the theories of Reasoned Action (Fishbein \& Ajzen, 1975) and Planned Behavior (Ajzen \& Madden, 1986) to be discussed more below, attitudes cause behavior through intentions that represent "the person's motivation in the sense of his or her conscious plan to exert effort to carry out a behavior" (Eagly \& Chaiken, 1993, p.168).

Researchers in psychology and education recognize attitudes toward science $(\mathrm{ATS})^{3}$ as an important construct for understanding participation in science. Osborne, Simon and Collins (2003, p.1049) explain that, "research indicating widespread scientific ignorance ... (and) the falling numbers choosing to pursue the study of science (make) the promotion of favorable attitudes towards science, scientists and learning science... increasingly a matter of concern." The situation has global implications. As the hinges of

\footnotetext{
3 A distinction should be made between the grammatically similar "scientific attitudes" and "attitudes toward science" construct (Gardner, 1975). Gardner (1975) made a useful demarcation that "scientific attitudes," or the ideal attitudes of an individual conducting science, are different than the evaluations of the institution of science by the lay public. Attitudes toward science, then, is an estimation of a population's positive or negative evaluation of the effects of science on the individual, society, and the environment.
} 
our sustainable strategy rely on science and technology (Fiksel, 2006; Kates, 2003;

World's Scientific Academies, 2000), not only will we need an enthusiastic student body in STEM, we will also need a public that is motivated to act in accordance with sciencebased information. In response to the National Science Board's (2009) request for "strategic engagement... to motivate appropriate individual consumer action" ( $\mathrm{p} 7$, italics added), the famous 1992 Earth Summit's message that "nothing less than a transformation in our attitudes and behavior would bring about the necessary changes," (United Nations, 1997, para. 2) surely applies to our attitudes toward science. 


\section{Attitudes, Culture, and Science}

The significance of attitudes toward science, or attitudes toward anything for that matter, is that they affect behavior. Attitudes are defined as an evaluation of an object of thought (Bohner \& Dickel, 2011, Fishbein, 1963). As an evaluation, attitudes can be positive, neutral, or negative and refer to a target of any kind, whether concrete (e.g. a university) or abstract (e.g. higher education), specific (e.g. Portland State University) or general (e.g. all universities; Eagly \& Chaiken, 1993). A review of the attitude literature by Bohner and Dickel (2011) reveals the complexity of the attitude construct; there have been debates about its character (stable or temporal), its process (e.g., automatic or

propositional), and its cognitive availability (explicit or implicit). Generally, research on attitudes has assumed the stable and explicitly available nature of attitudes and therefore relied on self-report measures.

As a latent construct, attitude cannot be directly observed. Attitude must be inferred from its cognitive (beliefs), affective (feelings), and conative (behavioral) expressions (Eagly \& Chaiken, 1993). However, since the early scale development work of Thurstone (1929) and Likert (1932), attitudes are primarily measured through their cognitive components (beliefs). Beliefs that frame the attitudinal object positively are combined with negative beliefs (usually reverse-scored) to calculate overall attitude toward the object (Anderson \& Fishbein, 1965; Osgood, Suci \& Tannenbaum, 1957). The same has been true for research in attitudes toward science, albeit with less rigor than in traditional attitude research (Pardo \& Calvo, 2002).

\section{The Theory of Reasoned Action and the Theory of Planned Behavior}


In the Theory of Reasoned Action (TRA), Martin Fishbein and Icek Ajzen (1975) outlined the process through which attitudes affect behavior. According to the TRA, when a positive attitude toward a behavior is combined with perceived approval from others, it results in the intent to act out that behavior. It is through these behavioral intentions that attitudes are translated into action.

TRA was eventually updated to include the attitude-bearer's perceived control over accomplishing his or her behavioral goal in Ajzen's Theory of Planned Behavior (TPB; Ajzen 1991; Ajzen \& Madden, 1986) (see Figure 1). TPB has been met with general support and has largely replaced TRA as a guide to research (Albarracín, Johnson \& Zanna, 2005). For instance, one study using structural equation modeling on two panel surveys of German-speaking Swiss participants found that the attitudes-norms-perceived control paradigm ascribed to in TPB accounted for roughly $80 \%$ of the variance in intentions to perform ecologically sound behaviors, and that those intentions account for $48-51 \%$ of the variance in a 65 -item checklist of ecological behaviors (Kaiser \& Scheuthle, 2003). In one meta-analysis of TPB research in general, Armitage and Connor (2001) found Azjen's model to account for 39\% of behavioral intentions, $27 \%$ of actual behavior and to explain significantly more variance than the TRA model. Other metaanalyses have supported TPB's utility for understanding things such as health behaviors (McEachan, Conner, Taylor \& Lawton, 2011).

While a substantial body of evidence exists for the TPB, the theory has not been empirically applied to attitudes toward science. TPB guided the development of James and Cardador's (2007) Cognitions and Beliefs about Technology and Science (CABATS) 
inventory, outlined further below. However validation work focused on specific beliefs rather than attitudinal composites of beliefs. According to the TPB model, positive attitudes toward science should predict intentions to participate in science-related activities when normative beliefs of relevant others and self-efficacy (i.e. perceived control) support participation. An adapted version of this model will be tested here (see Figure 1).

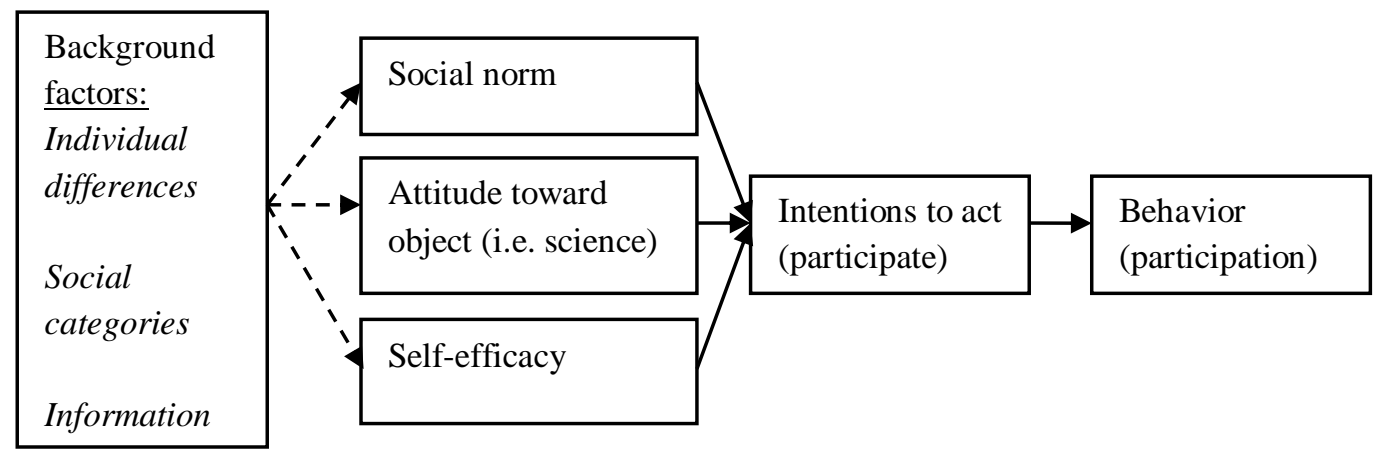

Figure 1. Ajzen's (1991) Theory of Planned Behavior (TPB) model with attitudes toward science (ATS) on participative behaviors with science.

\section{Attitudes toward science (ATS): A historical overview}

Research on attitudes toward science began in 1957 with a national study funded by the National Association of Science Writers to gauge the public's perception of science. There was a concern that society was growing cynical of the institution of science following such disturbing displays of technology as the atomic bomb (Pardo \& Calvo, 2002). The 1957 study is notable partly because it is a snapshot of American attitudes toward science prior to the Soviet Union's launch of Sputnik in 1957 and President Eisenhower's responsive National Defense Education Act of 1958 which energized math and science studies in the States (DOE, 2006; Laugksch, 1999). The resulting 1958 report by Robert C. Davis of the University of Michigan, The Public 
Impact of Science in the Mass Media, described a lack of scientific understanding as the cause for cynicism about science (Institute for Social Research at University of Michigan, 1958; Pardo \& Calvo, 2002). The described inverse relationship between the public's knowledge of science and negative attitude toward science guided research questions on ATS for three decades, although the next study did not occur until fifteen years later.

In 1973, 1975, and 1977 the National Science Board's Science Indicators studies distributed nationwide surveys with questions similar to the 1957 study about attitudes toward science. However, little to no theoretical progress was made until 1980 when Jon D. Miller joined the project and introduced the idea of adding attitudes toward specific technologies and dividing segments of the population into the science "attentive" and "inattentive" publics, according to the number of correct answers one delivered on twelve science textbook-like questions (see section The Problem of Scientific Illiteracy above). "Attitudes toward science and technology" took two forms; the first referred to specific controversial areas of research (stem cell and nuclear research or genetically modified foods) and the other to science "in general," where attitudes toward science basically comprised a) beliefs in the promise of science to solve humankind's problems and b) reservations (i.e. concerns) about science and technology.

The program run by Miller $(1983,1998,2004)$ emphasized the idea that knowledge and understanding of scientific discoveries and methods equated to some form of "science literacy," or the ability to read and write about science, necessary for civic participation in science and technology-related issues. The finding that individuals with more education (20+ years) and more college-level science classes reported more 
positive attitudes toward science provided evidence for the "deficit model," which predicted that people's lack of knowledge would lead them to hold negative attitudes toward science (i.e. to question, doubt, fear, or mistrust science as an institution; Pardo \& Calvo, 2002; 2004, see Figure 2).

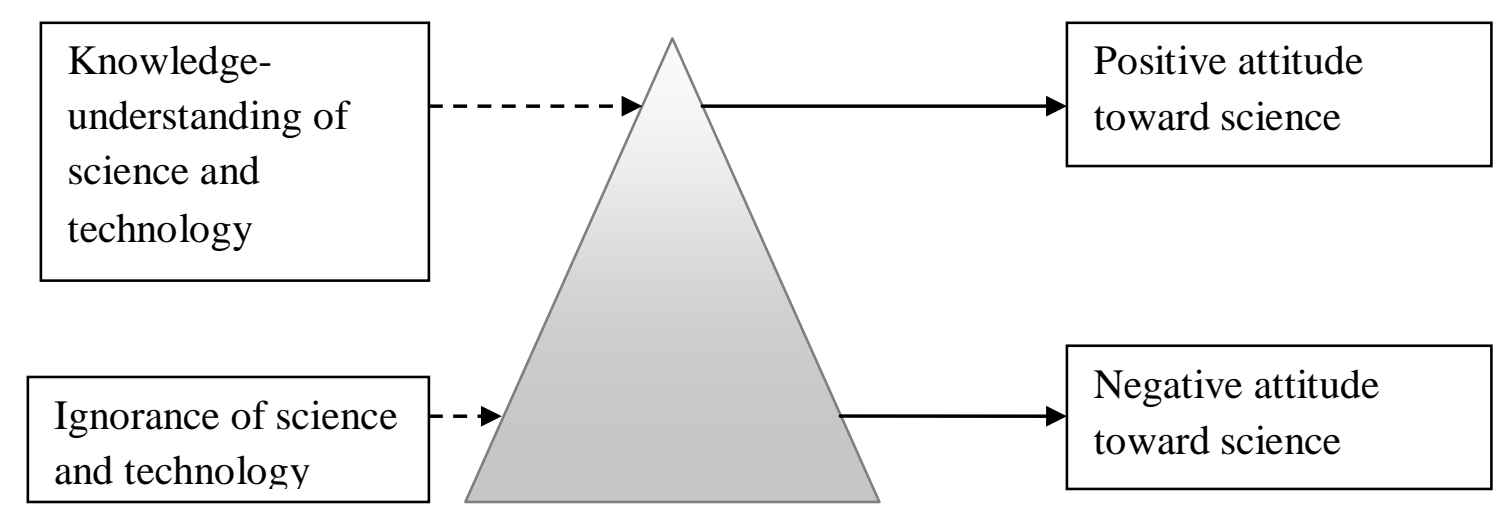

Figure 2. The "Deficit model" of attitudes towards science

Similar research campaigns developed around the world, beginning with the European Union in the early 1980's along with Miller's and spreading to France, Brazil, China, Canada, South Korea, India, Sweden, and Bulgaria in the late 1980's and 1990's (Bauer, Petkova, \& Boyadjieva, 2000). As data accumulated the deficit model's proposed relationship between science knowledge and positive attitudes toward science fell under scrutiny. Sometimes the relationship was present while other times it was not (Allum, Sturgis, Tabourazi \& Brunton-Smith, 2008). In a recent meta-analysis of data spanning 15 years, 40 countries, and 193 studies, Allum, Sturgis, Tabourazi, and Brunton-Smith (2008) largely settled the matter when they found a steady relationship between scienceknowledge to positive attitudes toward science. The effect, however, was small-tomedium in size after controlling for covariates in a multi-level model, which implied that 
knowledge of science, while definitely contributing to attitudes toward science, contributed little $($ beta $=.14, p<.01)$.

Research in the UK took national data in a somewhat different direction. In their landmark study, Bauer, Durant and Evans (1994) calculated science knowledge and attitude correlations by country within European Union and predicted those correlations with an "industrialization" index (GDP). They found a curvilinear relationship they labeled the "post-industrialization effect," where as countries increased in their gross domestic product (GDP) their attitudes toward science became more positive up until a point, after which positive attitudes declined and reservations about science increased. The "post-industrialization effect" revealed societal-level influences on our attitudes toward science.

\section{Contemporary Research on Attitudes toward Science (ATS)}

After the 2000's, in the wake of the deficit model's disappointing payoff, ATS research largely moved away from the "Science Literacy to Attitudes" paradigm to seeking other influences on ATS. While some research had looked at psychological factors to ATS early on, such technology's personal relevance (James, 1993) or one's religious values (Ellison \& Musick, 1995; Institute for Social Research at University of Michigan, 1958), ATS research as a whole has only recently ventured into psychosociocultural influences on perceptions of science. For example, varying sources of authority (Critchley, 2008), popular media (Jensen \& Hurley, 2010), health expectations (Connor \& Siegrist, 2010), and even modern science-based television dramas (Ley, Jankowski, \& Brewer, 2010) have been shown to influence ATS. 
Research exploring the persistent underrepresentation of females in high STEM positions has also found uses for ATS. In a study by Park, Young, Troisi and Pinkus (2011) changes in ATS were observed after a manipulation of romantic versus intellectual cues. In two experiments, women, but not men, tended to report decreases in positive ATS, less interest in pursuing a STEM field, and more interest studying English or a foreign language when shown romantic images or overhearing romantic conversation versus intellectual images or conversation. The authors argue that this is due to conflicting roles, where gender norms in Western cultures have traditionally promoted intellectualism in science as a competitive masculine activity (p. 1260).

The sustainability movement has motivated some researchers to seek to understand how ATS relates to environmental attitudes. Ignatow (2006), while not measuring ATS directly, presented a dual model for why individuals would be inclined to hold pro-environmental attitudes, one that was spiritual (tradition, religion-based) and one that was "ecological" (science-based). He found that individuals and nations high in formal education were more likely to adopt an ecological model of environmentalism where "science is embraced because ... [it] encourages the rational management of human-nature interactions" (p.444). Xiao (2011) used structural equation modeling on a nationally representative sample to find a reciprocal relationship between attitudes toward science and ecological worldview. Positive attitude toward science was negatively related to an environmentalist worldview, while, surprisingly, an environmentalist worldview was related to support for science and technology in solving global problems. Both 
Ignatow (2006) and Xiao (2011) found that education correlated with support for science and technology.

ATS's tradition in national indicator data combined with the interdisciplinary nature of the subject has caused several authors to comment on the lack of theoretical models and sound psychometric instruments (Allum, Sturgis, Tabourazi, and BruntonSmith, 2008; Blalock et al., 2008; Gardner, 1975; Pardo \& Calvo, 2002; 2004). Allum et al. (2008, p.39) describe the situation as thus:

"[T] he attitude scales that have been used in the NSF and Eurobarometer surveys are based on a somewhat ad hoc mixture of items, some of which go back to the original 1959 study... Pardo and Calvo (2002) present a reanalysis of the 1992 Eurbarometer survey on PUS (Public Understanding of Science) that suggests that there is, without doubt, a good deal of "fuzziness" in the various attitude scales that have been put to use by researchers over the years. They suggest more methodologically stringent and theoretically informed design for future attitudinal studies, whilst acknowledging that, as in the case of the knowledge scales, the existing measures are useful, if somewhat blunt, tools."

James and Cardador (2007), departing from typical single-item measures in ATS research, sought to develop an expanded inventory of Cognitions and Beliefs about Technology and Science (CABATS) guided by the Theory of Planned Behavior. College students rated their agreement with first and third person statements written to reflect science themes derived from a content analysis of available literature. Answers were then factor analyzed to reveal eight ways people think about science and technology. 
Of the eight dimensions, six have an evaluative element conducive with attitude research, where science and technology are viewed positively or negatively. The seventh involves identification with science and technology, and the last measures beliefs about what it takes to succeed in science. Positive beliefs about science and technology are that they offer economic advantage, prestige and enhance human capabilities. The negative belief dimensions involve (1) traditionalist sentiments, or the belief that new technologies lessen quality of life, and the beliefs that science and technology damage the (2) physical environment and (3) social world.

James and Cardador's (2007) validation study of the CABATS (Study 2) demonstrated the value of specifying particular dimensions of beliefs about science and technology. The CABATS inventory was used to predict the level of science in the disciplines that college students were studying and the careers that those disciplines would produce. Science involvement of disciplines was based on ratings by the heads of university departments. The belief that science is prestigious was found to predict the level of science involved in a student's major $($ beta $=.25)$, while traditionalism $($ beta $=$ .31 ) and the belief that science and technology cause environmental damage (beta $=-.14$ ) predicted lower levels of science in a student's major. Predictions using attitudinal composites of CABATS evaluative beliefs have not been explored.

The six evaluative beliefs of the CABATS provide a means of analyzing positive and negative attitudes toward science and technology separately, while relying on belief dimensions with known psychometric properties. Calculating positive and negative attitudes toward science separately is important as they have been found to be separate 
dimensions rather than opposite poles of a single continuum (Miller, 2004). Patterns of positive versus negative attitudes toward science have also been shown to be culturerelated. For instance, in Canada and the US, positive and negative attitudes correlated at .60 while they only correlated at -.11 in the European Union (p. 286).

James and Cardador (2007) also found that Caucasians, Asians, and males were significantly more likely to study high-science disciplines than were members of other groups. Osborne, Simon and Collins (2003) reviewed ATS research in K-12 education over the past 30-40 years and similarly report that Asians and Caucasians had more positive attitude towards science than members of other ethnicities, apparently because of a cultural valuation science based on perceived in-group benefit.

Miller (1998), father of the science literacy campaign, argued for the need to avoid the stigmatization inherent in deeming some "literate" and others not, where racial differences may have easily served as a proxy for other variables of interest (e.g. income, education). However, if attitudes toward science are confounded with cultural differences then it is important to directly investigate racial/ethnic/cultural differences in science attitudes. It is possible conceptualizations of science are influenced by ethno-cultural group membership, and that those conceptualizations influence STEM involvement. One aim of this study is offer evidence for such relationships.

\section{Culture and Inter-Group Effects on Attitudes toward Science}

An underlying motivation in studying ATS is to eventually foster conditions that facilitate broad participation in science, technology, engineering, and math (STEM). This is true in both for individual-level education (Augustine, 2007), and for societal-level 
participation in policy and legal issues such as environmental sustainability decision making (World Academies of Science, 2000). One way to discover conditions that encourage participation in STEM is to compare groups that have pursued science education and careers with those who have not. If members of the scientific community hold different attitudes toward science than members of an underrepresented cultural group (e.g. Native Americans) this would provide clues as to why membership in that cultural group is associated with lower rates of participation in science.

The notion that collectively held evaluations of (i.e. attitudes toward) people and things (e.g. policies, institutions, and behaviors) exist has been accepted in fields other than psychology for some time. For instance, the now famous political theorist Harold Lasswell (1927, pp.627-628, 629) wrote in his The Theory of Political Propaganda,

"Propaganda is the management of collective attitudes by the manipulation of significant symbols... Confusion has arisen principally because students have been slow to invent a word able to bear the connotation of uniformity without also implying a biological or metaphysical unity... If we state the strategy of propaganda in cultural terms, we may say that it involves the presentation of an object in a culture in such a manner that certain cultural attitudes will be organized toward it." Recognition of socio-cultural influences on attitudes (generally and toward science, in particular) has been slower in influencing the psychological literature. Sociocultural influences only surfaced in psychological theory over the past 30 years (Ajzen, 1991; Bronfenbrenner \& Morris, 1998; Hofstede, 1980).

In the recent Handbook on attitudes, Prislin and Wood (2005, p.672) formally acknowledge that attitude formation and expression are not purely individual-level 
processes, but rather "analysis of social and group influences on attitudes inevitably raises the issue of larger-scale societal and cultural effects" (p.695). They point out that across hundreds of studies all attitudes seem to serve the tripartite function of understanding the world, relating to others, and expressing one's identity (though the importance of each of these varies depending on the attitudinal object, the social context, and the goals of the individual).

Culture influences attitudes by providing goals and norms, shaping evaluations and approaches to understanding, and guiding self-concept development and expression (Festinger, 1954; Prislin \& Wood, 2005; Sherif, 1936). Triandis and Vassiliou (1972) named such influences "subjective culture," or the "attitudes, norms, roles, values, expectancies and other constructs" characteristic of a cultural group (Triandis, Malpass \& Davidson, 1973, p. 359). Hofstede (1980) called this the collective level of mental programming.

Albeit somewhat novel, the available literature supports the rationale that evaluating the effect of cultural group membership on attitudes toward science is a worthwhile endeavor. If a cultural group underrepresented in science (e.g. Native Americans) holds different cultural values, beliefs about and attitudes toward science than those espoused in the culture of science, this may shed light on collectively-held, value-based and attitudinal contributors to underrepresentation. This would imply, however, that science has a culture with which to compare.

\section{Science "Culture"}


The subjective human element in science has been well recognized since Kuhn (1970). The science community as a collective is subject to patterns and limits of cognition and behavior like any other defined human group. Hofstede (1980) wrote that as humans we are all subject to three levels of mental programming; the universal, the collective, and the individual. Universal mental programs are those which are found in people anywhere (e.g. associative and aggressive behaviors); individual mental programs are those unique combinations of experiences that make a person individual. The collective level of mental programming is a product of one's social environment (Hofstede, 1980).

As scientists put the principles of science into practice, comprise the scientific community, and both define its culture and define themselves by it (Poliakoff \& Webb, 2007), they provide the standard for assessing the values, normative beliefs and attitudes toward science conducive with STEM participation. Gardner (1975) described scientific attitudes as comprising an assortment of desired cognitive and affective drives that presumably are met through scientific inquiry and define the scientific community. They include a willingness to consider premises and consequences, a reverence for logic, and a desire to understand, to know, to verify, to question, and to search data for their meaning. It is probable that not all who practice sciences fully embody these virtues, yet these listed "scientific attitudes" effectively explain expectancies and roles of scientific valuebased norms, consistent with Triandis, Malpss and Davidson's (1973) definition of culture. 
Aikenhead and Ogawa (2007, pp. 544-551) distinguish mainstream science through twelve features that represent fundamental epistemologies, philosophical assumptions, values, goals, historical artifacts, or worldviews characteristic of scientific training and culture. The first of them are: 1) nature is knowable, 2) universal truth is possible, 3) the whole can be understood by its parts, 4) our measurement of reality reflects Reality, 5) Reality exists in distinct dimensions of matter and mind and, 6) objectivity is possible. The remainder deal with defining "knowledge" and begin with: 7) quantification, 8) replication and 9) generalizability. In addition, science defines knowledge as not created in a vacuum but within an: 10) infrastructure that gives priority to some pathways and interests over others through competitive processes, 11) utilizes mechanical/digital, rectilinear time and, 12) asserts its stewardship over all natural and human phenomenon.

It is not surprising then, in reflection of a similar list of scientific qualities, French psychologist Theodule Ribot (1906, p.255) boasted in his The Scientific Imagination, "the imagination of the great metaphysicians, by the originality and fearlessness of its conceptions, by its skill in perfecting all parts of its work, is inferior to no other form. It is equal to the highest, if it does not indeed surpass them." The above "subjective culture" of scientific norms, beliefs, attitudes, values, ideologies, sentiments, aspirations and the like support my use of a science-culture group in my study.

\section{Native American Culture and Science}

Native Americans were selected as a comparison group for four reasons: they are underrepresented in STEM (described above); there is evidence their cultural values are 
distinct from science's; their current and historical encounters with science and technological progress have been notably worse compared members of mainstream society; and Indigenous populations' potentially unique role in sustainability science and action. All of these reasons provide directions from which to draw expectations and make hypotheses. Therefore, this study compares scientists' cultural values, beliefs about and attitudes toward science with those of a Native American group.

Native cultural values. It has been noted in the science education literature that Native American culture differs from that of mainstream educational institutions. For instance, Pueblo educator Greg Cajete (1999) argues that Native students must negotiate different cultural systems depending on whether they are in the classroom or in their household or community. Pedagogical, conceptual, and behavioral norms that differ from home to school or university have been shown in some research to isolate students and lead them to be viewed as deviant or unengaged (see, e.g. Brayboy \& Maughan, 2009). Cajete (1999) describes fifteen interdependent cultural norms that can be put into six broader categories and that hinder positive relationships between teachers and Native students. The six categories are: collectivism, holism, pragmatism, present-orientation, social behavioral norms, learning style and work habits.

Aikenhead and Ogawa (2007, pp.556-564) offer a breakdown of ten cultural values, norms, and assumptions that they refer to as "Indigenous Ways of Living with Nature." Those include: 1) monism (vs. Descartes' dualism), 2) holism, 3) relationalism, 4) place-based metaphysics and spirituality, 5) dynamicism (iteratively adapting to their environment), 6) systematic (inter-generationally), 7) rational, 8) valid (or tested through 
observing consequences), 9) circular (vs. linear) time and 10) the notion of nature being in continually interconnected flux.

Given the range of potential differences between science and Native American culture as illustrated by the taxonomies just outlined, it important to focus on those general cultural values expected to influence attitudes toward science. Particularly valuable in that regard may be Kluckhohn's (1950) five primary components of all cultures that James (2006) has empirically linked to beliefs about science. Kluckhohn's core components are: 1) the predisposition of humankind (good, evil, neither/both), 2) time (past, present, future), 3) nature of being (being, being-in-becoming, doing), 4) humankind's relationship with nature (as subjugated to, in harmony with, or as having mastery over nature), and 5) modality of (social) relationship (lineal, collateral, individualistic).

Using an adapted inventory of Kluckhohn's cultural orientations, James (2006) correlated each orientation with scales on Anglo and Native American identity. He found that Native identity negatively correlated with individualism $(r=-.22)$ and mastery over nature $(r=-.22)$ but positively to the belief that mankind is basically good $(r=.32)$.

James (2006) then correlated the Kluckhohn value scores with his and Cardador's (2007) inventory of cognitions and beliefs about technology and science (CABATS). Individualism negatively correlated with the beliefs that science causes social $(r=-.42)$ and environmental ( $r=-.29)$ damage and was positively with the belief that science is prestigious $(r=.53)$. Mastery over nature likewise negatively correlated with the perceived environmental damage caused by science and technology $(r=-.30)$ and 
positively correlated with perceptions of science as heroic $(r=.41)$. Finally, the belief that human nature is essentially good correlated negatively with viewing science as intellectually enhancing $(r=-.27)$.

In these data we can see that Native identity correlates negatively with cultural values that tend to go with positive beliefs of science, and positively with cultural values that tend to go with negative beliefs about science. Anglo identity, on the other hand, correlated positively with individualism $(r=.38)$ and future time orientation $(r=.28)$. Future time orientation correlated with perceived environmental $(r=.18)$ and social damage $(r=.31)$ from science and technology. Reservations about science may be motivated by worry about the future within the Anglo community.

The above review provides justification to expect differences between science and Native cultural values concerning modality of human relationships, the predispositions of humankind, human-nature relations, and time orientation. Therefore, it is expected that scientists will differ from Native Americans on beliefs of: 1) individualism, 2) humanity’s inherent goodness, 3) humanity's dominion over nature, and 3) time orientation.

Exposure to science and technology. Attitudes toward science questionnaires partly tap perceived personal or in-group benefit (see National Science Board, 2012, chapter 7). Therefore, the extent to which any defined group has experienced scientific or technological benefits should determine the extent to which its members hold positive or negative attitudes toward science. 
The historical literature speaks to the often negative effects wrought on Native communities by mainstream society. For instance, Native Americans experienced a 9095\% drop in population following the arrival of white settlers as a result of a lack of immunity to European diseases, some of which were intentionally spread by non-Natives as they began to understand the spread of disease (e.g. General Jeffery Amherst or Captain Simeon Ecuyer). Similarly, technologies based on scientific advances were used in the campaign of the U.S. military against Native peoples (e.g. the Hotchkiss gun at “Wounded Knee Massacre;”'see also Bodley, 1999; Diamond, 1999; Thorton, 1987).

There were also other, direct and indirect, negative effects from science and technological progress on American's indigenous populations. Directly, colonization, large-scale agriculture, mining, dam building, waste storage and pollution, species extinction and other byproducts of supporting large immigrant populations changed the climate and environment in ways that disrupted traditional Native American modes of living (Lewis, 1995). Natural resource exploitation has often been the battleground where conflicting cultural values and ideas of environmental justice are embodied (James, Hiza, Hall, \& Doppelt, 2008).

Moreover, Native Americans were indirectly affected through assimilationist policies (e.g. boarding schools; relocation) intended to wipe out their traditional cultures (including languages, family names, and spiritualities) and force learning of and adoption of mainstream culture. In some areas, boarding schools provided a means of discrimination and abuse rather than educatoin. Just last year, the largest settlement from a religious institution ever ( $\$ 166.1$ million) was paid out to 450 Native Americans for 
sexual abuses that took place at Catholic boarding schools through the Northwest (Martinez, 2011).

Negative effects of science on Native groups continue today. The lingering effect of massive depopulation and subsequent subjugation on family, spiritual, and intrapersonal supports has been named historical trauma, which is said to ripple through the generations with measurable impact on depression, anxiety, anger, and shame, among others (Whitbeck, Adams, Hoyt \& Chen, 2004). Native communities report some of our nation's highest rates of suicide and homicide, infant mortality, violent crime, child abuse and neglect, and adolescent drug use (IHS, 1997; Walters, Simoni \& Evans-Campbell, 2002). Native Americans and Alaskan Natives continue to lead the nation in unemployment and poverty level incomes (Ogunwale, 2002). Native communities have a disproportionate amount of hazardous waste facilities on or near their land (Angel, 1991; Brook, 1998; Hanson, 2001), Native households are ten times as likely to be without electricity (EIA, 2000) and government protections (treaty agreements) of Native American's traditional food and natural resources are repeatedly violated in favor of farmers, corporate or political agendas (Hanson, 2001; Lewis, 1995, see also House Resolution 108 of 1953's Termination Act). Given the context, it is expected that Native Americans would 1) show apprehensiveness toward progress (traditionalism), and believe science and technology cause 2) social damage as well as 3) environmental damage.

Sustainability. In general, social research in "sustainability science" has been focused on deconstructing how "human institutions, economic systems, and beliefs shape interactions between societies and environments" (Kates, 2003, p. 140). The fourth 
motivation for comparing science and Native cultural groups' (see p. 26) has to do with Native American's unique contribution to the global transition to sustainability. In the Rio de Janeiro World Conference on Environment and Development (WCED), one of the United Nation's twenty-seven guiding principles of sustainable development stated, "Indigenous people... have a vital role in environmental management and development because of their knowledge and traditional practices. States should recognize and duly support their identity, culture and interests and enable their effective participation in the achievement of sustainable development." (United Nations, 1992, principle 22). President Obama similarly named tribal governments as important collaborators in achieving sustainable living within the U.S. (Council on Environmental Quality, 2010).

To enable indigenous participation across the natural and social sciences, a new field dedicated to collecting and understanding Traditional Ecological Knowledge (TEK) has burgeoned. One description of TEK offered by the Convention on Biological Diversity (CBD) provides a relatively comprehensive definition of the concept as currently conceptualized in most circles:

"Traditional knowledge refers to the knowledge, innovations and practices of indigenous and local communities around the world. Developed from experience gained over the centuries and adapted to the local culture and environment, traditional knowledge is transmitted orally from generation to generation. It tends to be collectively owned and takes the form of stories, songs, folklore, proverbs, cultural values, beliefs, rituals, community laws, local language, and agricultural practices, including the development of plant species and animal breeds. Sometimes it is referred to as an oral traditional for it is practiced, sung, 
danced, painted, carved, chanted and performed down through millennia. Traditional knowledge is mainly of a practical nature, particularly in such fields as agriculture, fisheries, health, horticulture, forestry and environmental management in general." (CBD Secretariat, n.d.).

There is evidence that TEK can have positive impacts on resource management (Berkes, Colding, \& Folke, 2000; Charnley, Fischer, \& Jones, 2007, Lertzman and Vredenburg, 2005), tracking environmental health indicators (Lauer \& Aswani, 2009; Garcia-Quijano, 2008), establishing an environmental ethic (Cistancho \& Vining, 2004), and settling disputes between government regulators and Native community members (Huntington, 2000). The acquisition of TEK has required innovative ways of applying research methods (Cristancho \& Vining, 2009) and facilitating indigenous community members into the research process (Huntington, 2000).

Indigenous contributions to "sustainability science" extend further than passive participation in scientific study. In James' (2001) edited work, Native community member training and education in science was deemed as a viable first step in addressing community needs by several authors. Similarly, Murry, James, and Drown (in press) found that education and science training are among the priorities identified by scientists and Native community members for sustainable Native community development. Once educated, Native scientists are thought to offer unique scientific perspectives based on cultural insights. Theoretical physicist F. David Peat (2002) describes how Native languages, cosmologies, medicines and stories contain ways of constructing reality that resemble recent theories of quantum physics. Cajete (2000) points out that the survival of Native people was due to their cultures' ability to incorporate ecological knowledge in 
individual and social behavior. He advocates for changes in science education to make space for Native voices in astronomy, psychology, and agriculture.

Whether to study TEK or to expand Native science, science and Native communities are coming together. Therefore, it is important to know how science and Native cultures are similar or different in their cultural values and attitudes toward science and what affect those values and attitudes have on collaboration between communities.

\section{Research Questions and Hypotheses}

My review of the literature uncovered two gaps in the research on attitudes towards science (ATS). ATS research has yet to apply an established theoretical framework to the ATS construct or evaluate the possibility of experience-based cultural antecedents to ATS. The aim of this study was to address both gaps in the research by 1)

importing Ajzen's (1991) Theory of Planned Behavior (TPB) model to evaluate ATS and 2) comparing ATS by groups that represent different cultures and experiences with science. These analytical goals were nested in national agendas to facilitate Indigenous involvement in sustainable development and increase Native American participation in science, therefore TPB was applied to science-related sustainability action intentions and ATS comparisons were made between scientists and Native Americans.

According to TPB, attitudes, normative beliefs, and self-efficacy predict intentions act. To evaluate whether ATS acts in accordance with attitudinal theory, I hypothesize that, beyond social demographic predictors: 
H1: ATS will predict intentions for science-related Native community sustainability actions, specifically where:

H1a: Positive attitudes toward science (pATS) predict an increase in intentions, and;

H1b: Negative attitude toward science (nATS) predict a decrease in intentions.

$\mathrm{H} 2$ : Cultural values (i.e. normative beliefs) will predict intentions for sciencerelated Native community sustainability actions, specifically:

H2a: Individualism will predict an increase in intentions,

$\mathrm{H} 2 \mathrm{~b}$ : The belief in humanity's inherent goodness will predict a decrease in intentions,

H2c: The belief that humans should have mastery over nature will predict an increase in intentions, and

H2d: Future time-orientation will predict an increase in intentions.

H3: Identification with science (i.e. self-efficacy) will predict an increase in intentions for science-related Native community sustainability actions.

To test whether general attitudes toward science could be culturally-based, I hypothesized that scientists and Native Americans would differ in that:

H4: Scientists would hold higher $p A T S$ than Native Americans, and H5: Native Americans would hold higher nATS than scientists.

Literature guiding these predictions also provided a basis to expect differences between scientists and Natives Americans on their cultural values and the specific beliefs 
about science and technology that comprise attitudes. In terms of cultural values, I hypothesize that:

H6: Scientists will be more individualistic than Native Americans,

H7: Native Americans will believe more in human goodness than scientists,

H8: Scientists will believe that humans should master nature more than Native Americans, and that

H9: Scientists will be more future time-oriented than Native Americans.

Specific beliefs about science and technology include identification with science, three positively-framed science beliefs, and three negatively-framed science beliefs. I hypothesize that;

H10: Scientists will identify with science more than Native Americans,

\section{Positive beliefs.}

H11: Scientists will believe that science offers economic advantage more than Native Americans,

H12: Scientists will believe that science enhances human capabilities more than Native Americans, and

H13: Scientists will believe that jobs in science offer prestige more than Native Americans. Meanwhile,

\section{Negative beliefs.}

H14: Native Americans will tend to prefer old ways over technological progress (traditionalism) more than scientists, 
H15: Native Americans will believe that science and technology cause social damage more than scientists, and

H16: Native Americans will believe that science and technology cause environmental damage more than scientists.

Due to sample size restrictions and the exploratory nature of this study, results will be reported at $\alpha=.05$ and .10 . Marginal significance will be interpreted for results between $.101-.15$. 


\section{Methods}

\section{Participants}

Participants for this study were attendees of one of two Indigenous Sustainability Workshops hosted by the Pacific Northwest Native Community Sustainability (PNWNCS) project (see pnwnativesustain.research.pdx.edu/). Therefore, the sample recruitment primarily focused on Native tribal leaders and community members within the region and scientists in academia and government involved in Native community relations or natural resource management near tribal lands (e.g., watershed preservation, land development, sustainable policy implementation).

Tribal members in this sample reported thirteen different tribal affiliations. Some were locally-based tribes (Oregon, Washington, Northern California, Alaska and British Columbia, Canada) while others were local residents with distally-based tribes (Colorado, South Dakota, Montana, and Hawaii). Recruitment yielded two different strains of science professionals. The first were those academics and government or private industry employees with a science education. The second were those whose professions involved mainstream-institution to Native American community relations regarding science information (e.g. health, education, employment).

A total of 66 workshop attendees participated in the study. Seven did not complete the full survey, leaving an $\mathrm{N}$ of 59 . Incomplete surveys did not show any notable trends compared to completed ones. Those who did not complete the survey did not differ significantly on education $(t(64)=-.09, p=.93)$, gender $(t(64)=.37, p=.71)$, or participation in organized religion $(t(60)=.53, p=.60)$, but did differ significantly 
differ on race $\left(\chi^{2}(6)=18.31, p=.006\right)$. Hand calculations of risk ratios for each racial category show the differences to be driven by African Americans and Pacific Islanders, in that every other racial category had a zero or near zero risk of leaving their survey incomplete. African Americans were equally likely to complete as not (i.e. two of four; $\mathrm{n}=4$ ), and Pacific Islanders were 1.5 times as likely to leave a survey incomplete (i.e. two of three; $\mathrm{n}=3)$. Non-completers only finished between $7-26 \%$ of the survey $(M=15.14 \%$, $\mathrm{SD}=7.78)$ so they were not included in these analyses.

Of the fifty-nine participants whose data were analyzed, most were Caucasian $(60 \%)$ and female $(64 \%)$. Average age was 39.22 (range $=21-68, \mathrm{SD}=13.44)$. A quarter of the sample was Native American/Alaskan Native/Hawaiian Native/First Nations ${ }^{4}$ $(\mathrm{n}=15,25 \%)$. No other ethnic group (e.g., Asians) comprised more than $3.4 \%$ of the sample. About half ( $\mathrm{n}=7,53.8 \%)$ of the Native Americans classified themselves as urbanbased (versus reservation-based), of mixed ethnicity (versus both parents being Native; $\mathrm{n}=8,53.3 \%)$, and federally/state enrolled $(\mathrm{n}=9,60 \%)$. About half spoke a Native language $(n=7,47 \%)$, two-thirds had parents who spoke a Native language $(n=10,67 \%)$, $87 \%$ attend traditional ceremonies, and $100 \%$ recognize traditional religion.

The "Scientist" classification depended on one's self-reported field of study or occupation. Therefore, an individual who said their field of study was, "earth sciences," “chemistry," "engineering," “math," "physics," "biology," "technology,” or the like was coded as a scientist. Thirty-three participants were scientists by this standard (56\%) including four Native Americans. Thirteen participants (22\%) were from applied-science or policy professions/studies, (e.g. "land use policy analyst," "Forestry marketing"). They

\footnotetext{
${ }^{4}$ From here on referred to simply as Native American or Native.
} 
were combined with the hard scientists to form the scientist group. Of the remaining $22 \%$ eleven (19\%) were Native American and thus coded into Native American group. Two participants failed to answer the question (.03\%).

Scientists and Native Americans did not significantly differ on gender $(t=-.16, p$ $=.87, \mathrm{CI}(90 \%)-.27--.22)$, participation in organized religion $(t=-1.52, p=.13$, $\mathrm{CI}(90 \%)-.44--.02)$, or education $(t=-.68, p=.50, \mathrm{CI}(90 \%)-.88--.37)$. Forty percent of the Natives and $43 \%$ of the scientists had a Bachelors' degree, $27 \%$ of the Natives and $19 \%$ of the scientists had a master's degree, and $19 \%$ of Natives and $19 \%$ of scientists had a doctorate.

\section{Procedure}

Participants were asked to volunteer to take the survey to help inform collaborations between scientists and Natives of some of their similarities and differences. All participants except one took the survey online; one participant completed a paper survey, meaning that differences between online versus paper administration could not be conducted.

Anonymous survey links were emailed in invitations for the Indigenous Sustainability Workshops. Participation was not required to register. No incentives were given for participation apart from the notification that data would go to help collaborations for sustainable Native community research.

\section{Measures}

The questionnaire consisted of four sections; demographics, cognitions and beliefs about science and technology, cultural values, and sustainable priorities. To test 
Ajzen's Theory of Planned Behavior (TPB) in hypotheses 1-3, I needed measures for attitudes, self-efficacy, normative beliefs, and intentions. General positive attitude toward science and general negative attitude toward science were derived from composites of positive and negative beliefs about science (see ATS in preliminary analyses), selfefficacy was measured through identification with science, normative beliefs were measured as pro-scientific versus pro-Native cultural values, and intentions were measured through sustainable action priorities. Comparisons in hypotheses 4-16 similarly use the composites of positive and negative attitudes, along with cultural values and specific beliefs about science (i.e. identification with science, each positive belief about science, and each negative belief about science).

Beliefs about science. To measure participants' beliefs about science I used an adapted version of James and Cardador's (2007) Cognitions and Beliefs about Technology and Science (CABATS) inventory. This inventory contained subscales for identification with science, along with three positively-framed beliefs about science and three negatively-framed beliefs about science from which to infer attitudes. Six items from the version in James and Cardador were not used; each of the deleted items had a similar item remaining on the inventory (see Appendix B), so the breadth of the inventory was not compromised. Sub-scales have been shown to have adequate internal consistency (average alpha $=.72$ ), and reasonable evidence of scale validity has also been developed (see James \& Cardador, 2007; and James, 2006). The labeled dimensions are organized by their use in this study.

Positive Beliefs about Technology and Science 
1. Economic advantage $(i=4)$ : The belief that science and technology are crucial for individual and national economic competitiveness (e.g. 'New technologies provide many economic benefits.").

2. Human capability enhancement $(i=6)$ : The belief that science and technology are improving the human race/condition (e.g. "Science has enhanced the skills of modern youth").

3. $\quad$ Prestige $(i=6)$ : Feelings of high regard for people who do science (e.g. "I admire people who work in science.”).

Negative Beliefs about Technology and Science

4. Traditionalism $(i=6)$, or the preference for old ways of life and doing things, (e. g. "Because of changes in technology, most people today feel little connection with the past").

5. Social damage $(i=6)$ : The belief that science and technology diminish human relations (e. g. "Interactions with other people are greatly reduced in scientific professions").

6. Environmental damage $(i=6)$ : The belief that science and technology are the cause of environmental degradation (e. g. "Modern science is the major cause of damage to the physical environment").

Self and Technology/Science

7. Identification with science $(i=3)$, agreement that people similar to myself are successful in science (e. g. "People my age are better at learning new technologies than people of other ages"). 
8. $\quad$ Success in science $(i=7)$, ideas of what it takes to be good at science (e. g. "Careers in science require taking high personal initiative and personal responsibility"). ${ }^{5}$

Cultural values. Cultural values were assessed through a measure based on Kluckhohn's cultural inventory was taken from James (2006). The inventory consists of fifteen statements, each representing one of three cultural resolutions to five core existential questions. Seven single-item measures (resolutions) were used here, in accordance with my hypotheses, although three pairs of these items represented opposite ends of a value continuum and so were combined to create a single cultural value for each of the three pairs. Individualism did not have an opposing science-Native cultural value (ideally collectivism) within the Kluckhohn inventory so it stood alone (item $n(i)=1)$.

Two items representing opposite ends of each science-Native cultural continuum were used for human's relationship with nature (humans are at the mercy of nature v have mastery over nature; $i=2$ ), human predisposition ( evil $\mathrm{v}$ good; $i=2$ ), and time orientation (present $\mathrm{v}$ future; $i=2$ ). Each variable was averaged after reverse coding the non-referent variable. For example, a higher human-nature rating means a stronger belief in mastery, a higher human predisposition rating means a stronger belief in human goodness, and a higher time orientation score means a stronger future time-orientation. Example items are:

1. Individualism: "I believe in being independent and free from control."

2. Human nature: "Most people are mainly good hearted" (human goodness).

\footnotetext{
${ }^{5}$ The literature surrounding my particular research question did not suggest hypotheses for this dimension so it was not included in these analyses. It was included here for the sake of completeness in describing the measure.
} 
3. Humankind's relationship with nature: "Technology will eventually allow humans to completely control nature" (mastery over nature).

4. Time orientation: "I mainly live my life day to day, not worrying about the past or the future" (present orientation).

Sustainable intentions. Hypotheses 1-3 contain predictions about sustainability action priorities. Items reflecting this construct came from the Native Climate Action and Research Priorities (NCARP) inventory. NCARP was derived from a list of sustainable research and action priorities from a 2008, NSF-funded Native Climate Decision Catalyst project. Native community leaders and members and representatives from the National Center for Atmospheric Research and the US Geological Survey collaborated to identify priority 1) action plans and 2) research efforts for sustainable Native community development. Action plans were selected for dependent variables with the rationale that prioritizing actions for Native community sustainability prior to attending an Indigenous Sustainability Workshop a) may function as an intention to carry out action priorities and therefore b) fit into Ajzen's (1991) Theory of Planned Behavior's predictive model. Action priorities consisted of 20 items that range from environmental to social action. Items were rated in terms of importance on a 7-point Likert-type scale from not important at all to very important. Sample items include:

1. "More and better collaboration between and among local communities."

2. "Develop approaches to conflict resolution and collaboration between scientists and community members."

3. "Link human physical health to community environmental sustainability." 


\section{Analyses}

Reliability, descriptive, and correlation statistics were examined prior to hypothesis testing. Then correlations were used to examine the interrelationship between variables. This was done partly to examine multicolinearity among dependent variables but also to provide evidence that the variables were acting in accordance with theoretical expectations. To assess the effect of cultural group membership, a dichotomous variable was created to represent the scientist versus Native American group membership.

To test hypotheses 1-3, I used a hierarchical regression to evaluate the unique contribution of attitudes toward science in addition to testing the full TPB model. In the first step, gender, cultural group membership (scientist versus Native), and membership in an organized religion were entered as covariates, or social demographic predictors. In step two, cultural values (i.e. normative beliefs) and identification with science (i.e. selfefficacy in science) were entered as a partial model. In step three, general positive attitude toward science and general negative attitude toward science were entered to evaluate the full TPB model and examine the unique effect size of general positive and negative attitudes toward science on intentions to act for science-related sustainability action for Native communities.

Hypotheses 4-16 were evaluated using 2x2 Factorial MANCOVA’s, where selfidentified gender (male and female) and scientist versus Native identification were entered as independent variables. Membership in an organized religion was entered as a covariate (see preliminary analyses below for justification). I used the conservative Pillai's trace statistic to test multivariate differences instead of the more common Wilk's 
Lambda, as this statistic is robust against violations to test assumptions, such as unequal variances, cell and sample sizes, all of which are present in this sample. No post-hoc tests were necessary as there were no more than two levels for each independent variable. When pairwise comparisons were appropriate, they were made using Bonferroni corrections for type-1 error. I entered dependent variables in sets of 1) overall attitudes toward science (hypotheses 4-5), 2) cultural values (6-9), and 3) specific beliefs about technology and science (10-16). This was done as each set of dependent variables represented separate conceptual levels and to avoid the loss of power that takes place when cells have fewer participants per cell than DV's. 


\section{Results}

\section{Preliminary Reliability, Descriptive, and Correlation Analyses}

Prior to running reliability and descriptive analyses, a decision had to be made for the four Native scientists in this sample. Comparisons could not be made between scientists and Native Americans if certain members occupied both groups. Native scientists belonged to the scientist group by education but were equal in exposure to Native culture (e.g. Native language) with Native non-scientists. Empirically, Native scientists' average ratings were closer to scientist ratings on seven of the twelve variables hypothesized to differ between scientists and Native Americans. However, pairwise comparisons failed to identify any significant differences between Native scientists and Native non-scientists or non-Native scientists $(p<.10)$ with a Bonferroni correction. The degree to which they belonged to scientist or Native American categories therefore could not be assessed. Due to the fact that Native scientists' dual group membership was confounding, they were excluded from further analyses, resulting in a final $\mathrm{N}$ of 55 . Given the sample size and the exploratory nature of this study, results will be considered significant at $\alpha=.05$ and .10 in order to increase power to find an effect. Marginal significance will be interpreted at the $\alpha \leq .15$.

Scientists and Native Americans (without Native scientists) did not significantly differ on gender $(t=.04, p=.97, \mathrm{CI}(90 \%)-.27--.28)$ or education $(t=-.14, p=.89$, CI(90\%) -.76 -- .67). Scientists and Native Americans differed in their participation in organized religion with marginal significance $(t=-1.57, p=.12, \mathrm{CI}(90 \%)-.48--.02)$, in that Native American non-scientists (from here on referred simply as Native Americans) 
were members of an organized religion more than Scientists. This is important as membership in organized religion has been associated with negative attitudes with science (Ellison \& Musick, 1995). Consequently, membership in an organized religion was included as a covariate in hypothesis tests.

Attitudes towards science (ATS). Hypotheses 1, 4 and 5 include predictions involving positive attitude toward science (pATS) and negative attitude toward science (nATS). PATS and nATS were determined through averaging across evaluative (positive and negative) belief dimensions of the James and Cardador's (2007) Cognitions and Beliefs about Technology and Science (CABATS) inventory. Justification for the composites came from Likert's (1932) method of attitudinal assessment, whereby items are factor analyzed to determine their evaluative position and strength on an attitudinal continuum (see review in Kronisk, Judd, \& Wittenbrink, 2005). A principal components analysis was run on the three positive (economic advantage, human enhancement, and prestige) and three negative beliefs (social damage, environmental damage, traditionalism). The analysis produced one component that explained $54.12 \%$ of the variance (eigenvalue $\geq 2$ ). One component supported the idea that these variables represent positive and negative ends of an attitudinal continuum. Negatively framed science-beliefs had a high average loading (-.88) however positively framed sciencebeliefs were much lower (.54). A look at the variable loadings revealed that this was caused by the positive belief prestige, which loaded below the conventional cut of .4-.5 $(.23)$. 
A second principal components analysis without prestige produced one component that explained $64.23 \%$ of the variance (eigenvalue $>2$ ). Negative beliefs had an average loading of -.88 , while positive beliefs had an average loading of .67. This solution provided a more clear representation of the positive and negative ends of the attitudes towards science continuum, and was therefore preferable to the solution above. Including prestige in the composite did not substantially change the results of any analyses. However, excluding prestige meant that positive attitude toward science could be defined by beliefs that captured the higher end of that continuum, aiding interpretation and clarity of the construct. After considering additional issues with the prestige subscale's low internal consistency, it was not included in the attitudinal composite.

Despite the single component structure, positive and negative attitude composites were calculated separately as they have been found to correlate differently across cultures (Miller, 2004). Internal consistency was slightly below the conventional .70 for positive attitude toward science (pATS; $\alpha=.65$ ). Negative attitude toward science (nATS; $\alpha=$ .90) met conventional standards of internal agreement. Average ratings were near the mid-point rating (neither agree/disagree) for positive attitude toward science (pATS) ( $M$ $=4.35, \mathrm{SD}=.81)$ and negative attitude toward science $(\mathrm{nATS})(M=4.09, \mathrm{SD}=.95)$. PATS significantly negatively correlated with nATS $(r=-.55, p=.001)$. This correlation is low enough to be considered separate constructs, although issues of multicolinearity may be a concern in hypothesis testing that includes both variables. The -.55 correlation is in line with (inter)national estimates throughout North America ( $r=-.60$; Miller, 2004). 
Cultural values. I tested hypotheses $2 \mathrm{a}-2 \mathrm{~d}$ and 6-9 with seven cultural values argued in the literature to characterize science versus Native cultures. Individualism (hypothesis $2 \mathrm{a}$ and 6 ) consisted of a single-item measure so no reliability analyses could be run without a test-retest occasion. For hypotheses $2 b-2 d$ and 7-9, three pairs of values representing different ends of cultural value continuums (e.g. humans are essentially good v humans are essentially evil) were averaged after reverse-coding the non-referent variables (e.g. evil), reducing the total number of cultural values from seven to four. Internal consistencies between the referent item and reverse scored item were low for mastery over (v at mercy of) nature $(\alpha=.23)$ and future (v present) time-orientation $(\alpha=$ .23). Only human goodness had traditionally acceptable internal consistency $(\alpha=.74)$. The low internal consistencies for mastery and future time-orientation reveal how dichotomizing these cultural values creates contrived continua (e.g. present v future).

Descriptive statistics show that the average rating for the sample as a whole $(\mathrm{n}=55)$ was near the mid-point rating on individualism ${ }^{6}(M=4.53, \mathrm{SD}=1.43)$, agreed that humans are mainly goodhearted rather than $\operatorname{evil}^{7}(M=5.74, \mathrm{SD}=1.04)$, believed that we are at the mercy of nature more than the master of it $(M=2.35, \mathrm{SD}=1.01)$, and were more future-time orientated than present-time orientated $(M=5.25, \mathrm{SD}=.98)$. Individualism significantly negatively correlated with the belief in human goodness $(r=-$ $.27, p=.05)$ and mastery over nature $(r=-.26, p=.051)$, although the strength of the

\footnotetext{
${ }^{6}$ NOTE: Ratings were given on a 7-point scale where $4=$ neither agree nor disagree. The higher a mean is above 4.00 , the stronger the average agreement; the lower a mean is below 4.00 , the stronger the disagreement.

${ }^{7}$ NOTE: Ratings on goodness ( $\mathrm{v}$ evil), mastery ( $\mathrm{v}$ mercy), and future (v present) time-orientation represent value continuums. Therefore a rating of 4 on these variables represents either equal holding of opposing values or indifference to either value. A rating above or below 4 indicates stronger agreement with one of the two opposing cultural values.
} 
relationships caused no concern of multicolinearity. Future time-orientation did not correlate with any of the other cultural values.

Sustainable action priorities. Sustainable action priorities served as the dependent variable for hypotheses 1-3. Internal consistency met conventional standards $(\alpha=.96)$ and a principal components analysis using varimax rotation identified one component (eigenvalue > 2) explaining 59.34\% of the variance. A composite score was created averaging across items. Participants rated the list of sustainable actions as an important on average $(M=6.15, \mathrm{SD}=.74)$.

Beliefs about science. I tested hypotheses 3, and 10-16 utilizing seven of the eight sub-scales in James and Cardador's Cognitions and Beliefs about Technology and Science (CABATS) inventory. It would be ideal to validate the factor structure with confirmatory factor analyses in both the entire sample and by comparison group, however, the sample size is not sufficient to provide reliable estimates for exploratory or confirmatory factor analyses. Therefore, it was necessary to rely on the dimensions as they were defined in James and Cardador's 2007 validation study.

Tests of internal consistency using Cronbach's alpha on each subscale show acceptably high agreement within three of the seven dimensions utilized here; traditionalism $(\alpha=.75)$, social damage $(\alpha=.86)$, and environmental damage $(\alpha=.83)$. Therefore composite scores were created based on the items available from the original scale for each subscale. Average ratings in traditionalist sentiments $(M=4.22, \mathrm{SD}=.89)$ and beliefs that science and technology cause social damage $(M=4.37, \mathrm{SD}=.95)$ or environmental damage $(M=3.67, \mathrm{SD}=1.27)$ were close to mid-point on the rating scale 
(neither agree/disagree). Neutrality was well within one standard deviation of the mean for each variable. The other four dimensions failed to meet acceptable levels of internal consistency: identification with science and technology $(\alpha=17)$, economic advantage $(\alpha$ $=.44)$, human capability enhancement $(\alpha=.56)$, and prestige $(\alpha=.33)$.

The identification with science subscale contained three items, one each pertaining to age, race, and gender. Low internal consistency was the result of the race item, "My ethnic/racial group is good at developing new technology," which correlated negatively with the other items at $r=-.17$ on average. Removing this item increased Cronbach's alpha by .44 $(\alpha=.61)$. Although the internal consistency was still lower than the conventional standard of .70, I considered the increased alpha high enough to proceed with a composite of the remaining two items. Average identification with science was below the mid-point on the rating scale, leaning toward not identifying with science, however the standard deviation shows considerable spread $(M=3.49, \mathrm{SD}=1.44)$.

Inter-item correlations within the subscale economic advantage revealed two items that correlate particularly low and sometime negatively with other items. "The United States as a nation needs to both use and create new technologies in order to compete with foreign countries" correlated with other items at $r=-.32$ on average. Removing this item increased Cronbach's alpha by .27 $(\alpha=.71)$. The second item, "The economic competitiveness of the United States depends on our ability to use and create new scientific information," had an average inter-item correlation of $r=.11$. Alpha increased by another .04 $(\alpha=.75)$ when this item was removed. Composite scores were 
created for economic advantage with the remaining four items. Average ratings were neutral that science and technology offer economic advantage $(M=4.41, \mathrm{SD}=1.02)$.

The human capability enhancement subscale contained two items that correlate particularly low and sometimes negatively with the other items. "Modern technology has made today's children ignorant (reverse coded)" and "Technology is wasted in making toys and games (reverse coded)" correlated with other items at .17 and .13 on average. Therefore these items were not included in the composite score of capabilities enhancement. The resulting alpha increased by .02 $(\alpha=.58)$. I considered the increased alpha high enough to proceed with a composite of the remaining four items. Average ratings were neutral in the belief that science and technology enhance capabilities $(M=$ 4.30, $\mathrm{SD}=.86)$

Items within the prestige subscale were weakly correlated on average $(r=.08)$. "People who work with advanced technology are independent" and "I believe that the people who control science today generally have values similar to mine" correlated with each other at $r=.26, p=.049$, but the two items correlated negatively $(r=-.04)$ or barely at all $(r=.04)$ with other items on average. Dropping these items improved the alpha by $.08(\alpha=.41)$, however, acceptable levels of internal consistency could not be achieved given the generally low inter-item correlations. A composite was nevertheless created with the remaining items. Results from analyses on this dimension should be interpreted with caution. Average ratings on this dimension were near the mid-point on the scale $(M$ $=3.91, \mathrm{SD}=.81)$. 
There were many inter-correlations between the seven CABATS dimensions analyzed here. Identification with science significantly positively correlated with traditionalism $(r=.29, p=.04)$ and beliefs that science and technology cause social damage $(r=.25, p=.07)$ and environmental damage $(r=.31, p=.02)$. Identification with science correlated negatively with the belief that science provides economic advantages $(r=-.23, p=.09)$ and enhances human capabilities $(r=-.36, p=.007)$.

Economic advantage correlated positively with capability enhancement ( $r=.49, p$ $<.001)$ and prestige $(r=.28, p=.04)$ and negatively correlated with traditionalism $(r=-$ $.41, p=.002)$, social damage $(r=-.44, p=.001)$, and environmental damage beliefs $(r=-$ $.44, p=.001)$. Similarly, capabilities enhancement significantly positively correlated with prestige $(r=.47, p<.001)$ and negatively correlated with traditionalism $(r=-.43, p=$ $.001)$ social damage $(r=-.53, p<.001)$, and environmental damage beliefs $(r=-.40, p=$ $.002)$. Traditionalism correlated positively with both social damage $(r=.74, p<.001)$ and environmental damage beliefs $(r=.77, p<.001)$ and social damage and environmental damage correlated positively with each other $(r=.80, p<.001)$. The strength and direction of these correlations supports the notion that these evaluative (positive and negative) beliefs together represent an overarching attitudinal construct. Positive beliefs about science correlate positively with other positive beliefs about science and negatively with negative beliefs about science and vise versa. The issue of mulitcolinearity may be a concern for negative beliefs (hypotheses 14-16), as their intercorrelations average at .77 .

\section{Hypothesis testing}


Seven of sixteen hypotheses were supported (see Table 1). One hypothesis was significant but only through an interaction (H11) and one hypothesized relationship was significant but in the unexpected direction (H13). A breakdown of the results follow in each subsection.

Table 1. Summary overview of supported hypotheses.

\begin{tabular}{|c|c|c|}
\hline Hypotheses supported & Yes & No \\
\hline Testing Ajzen's Theory of Planned Behavior (TPB) & & \\
\hline $\begin{array}{l}\text { H1: Attitudes toward science (ATS) on intentions to act on science- } \\
\text { related sustainability priorities }\end{array}$ & & \\
\hline 1a: Positive ATS (pATS) predicts increase in intentions & $\mathrm{X}^{* *}$ & \\
\hline 1b: Negative ATS (nATS) predicts a decrease in intentions & & $\mathrm{X}$ \\
\hline $\mathrm{H} 2$ : Normative beliefs on intentions & & \\
\hline 2a: Individualism predicts increase in intentions & $\mathrm{X}^{*}$ & \\
\hline $\begin{array}{l}\text { 2b: Belief in human goodness (v evil) predicts a decrease in } \\
\text { Intentions }\end{array}$ & & $\mathrm{X}$ \\
\hline $\begin{array}{l}\text { 2c: Belief that humans should master nature ( } \mathrm{v} \text { be at nature's } \\
\text { mercy) predicts increase in intentions }\end{array}$ & & $\mathrm{X}$ \\
\hline $\begin{array}{l}\text { 2d: Future (v present) time-orientation predicts increase in } \\
\text { intentions }\end{array}$ & & $\mathrm{X}$ \\
\hline H3: Self-efficacy predicts increase in intentions & & $\mathrm{X}$ \\
\hline Testing a cultural basis for ATS & & \\
\hline $\begin{array}{l}\text { H4: Scientists will have significantly higher pATS than Native } \\
\text { Americans (NA's) }\end{array}$ & & $\mathrm{X}$ \\
\hline H5: NA's will have significantly higher nATS than scientists & $\mathrm{X}^{* * * *}$ & \\
\hline Testing cultural value differences between scientists and NA's & & \\
\hline H6: Scientists will be more individualistic than NA's & & $\mathrm{X}$ \\
\hline H7: NA's will belief more in human goodness than scientists & & $\mathrm{X}$ \\
\hline $\begin{array}{l}\text { H8: Scientists will believe humans should master nature more than } \\
\text { NA's }\end{array}$ & $\mathrm{X}^{\dagger}$ & \\
\hline $\begin{array}{l}\text { H9: Scientists will be more future (v present) time-oriented than } \\
\text { NA's }\end{array}$ & & $\mathrm{X}$ \\
\hline $\begin{array}{c}\text { Testing differences between scientists' and NA's beliefs about } \\
\text { science }\end{array}$ & & \\
\hline H10: Scientists will identify with science more than NA's & & $\mathrm{X}$ \\
\hline $\begin{array}{l}\text { H1 1: Scientists will believe that science offers economic advantage } \\
\text { more than NA's }\end{array}$ & $I^{\dagger}$ & \\
\hline $\begin{array}{l}\text { H12: Scientists will believe that science enhances human } \\
\text { capabilities more than NA's }\end{array}$ & & $\mathrm{X}$ \\
\hline $\begin{array}{l}\text { H13: Scientists will believe that careers in science are prestigious } \\
\text { more than NA's }\end{array}$ & & $\mathrm{U}^{*}$ \\
\hline H14: NA's will be more traditionalist than scientists & $\mathrm{X}^{* *}$ & \\
\hline $\begin{array}{l}\text { H15: NA's will believe that science causes social damage more } \\
\text { than scientists }\end{array}$ & $\mathrm{X}^{* *}$ & $I^{*}$ \\
\hline $\begin{array}{l}\text { H16: NA's will believe that science causes environmental damage } \\
\text { more than scientists }\end{array}$ & $\mathrm{X}^{* *}$ & \\
\hline
\end{tabular}


significance); $\mathrm{X}=$ Supported, I = Interaction with gender, $\mathrm{U}=$

Significant but in the unexpected direction.

\section{Attitudes toward Science (ATS) and the Theory of Planned Behavior (TPB).}

In hypotheses 1a-3, I made predictions based on the Ajzen's (1991) model of attitudes. I hypothesized that attitudes toward science (H1a-1b), cultural values (normative beliefs; H2a-2d), and identification with science (self-efficacy; H3) would predict an increase in intentions to perform science-related sustainability planning actions. To test these predictions, I ran a hierarchical linear regression entering demographic variables in step 1 , cultural values and identification with science in step 2 , and then, to examine the unique contribution of ATS, in step 3 I added positive attitude toward science (pATS) and negative attitude toward science (nATS). Intentions to perform science-related actions for Native community sustainability served as the outcome variable.

Step 1 variables included cultural group membership (scientist or Native), gender, and membership in an organized religion. Step 1 explained 7\% of the variance in action priorities, although none of them were significant predictors $(p<.10)$. The step did not lead to a significant change in the $F$-statistic, $F(3,42)=.97, p=.42, \mathrm{R}^{2}=.07$. In step 2, I added identification with science (i.e. self-efficacy) and the cultural values (i.e. normative beliefs) that were identified in the literature as differing between science and Native cultural groups. This step did not produce a significant change in the F-statistic, however it did explain an additional $9 \%$ of the variance, $F \Delta(5,37)=.78, p=.57, \mathrm{R}^{2}=.15$.

In step 3, I entered pATS and nATS, explaining an additional $12 \%$ of the variance in intentions to act for Native community sustainability. The step lead to a significant change in the $F$-statistic, $F \Delta(2,35)=2.95, p=.07, \mathrm{R}^{2}=.28\left(\operatorname{adj~} \mathrm{R}^{2}=.07\right)$. 
The relationship between pATS and intentions to act for Native community sustainability was positive, in that for every one unit increase in pATS sustainable action intentions increased by about two-fifths of a unit, $\beta=.42, p=.02, \mathrm{CI}(90 \%)=.13-.71$. This supports hypothesis 1a. Negative attitude toward science did not significantly predict intentions, $\beta=.22, p=.21, \mathrm{CI}(90 \%)=-.07-.51$, and the positive beta-weight directly contradicts hypothesis $1 \mathrm{~b}$. The cultural value of individualism significantly positively predicted intentions controlling for other variables in step $3, \beta=.15, p=.08, \mathrm{CI}(90 \%)=.007-.29$. This is in support of hypothesis $2 \mathrm{a}$. The covariate, membership in an organized religion, marginally significantly predicted a decrease in intentions to act for science-related Native community development, $\beta=-.42, p=.12, \mathrm{CI}(90 \%)=-.86--.03$. The results are presented in Table 2 .

\begin{tabular}{|lccccc|}
\hline \multicolumn{6}{|l}{ Table 2. Full model summary of hierarchical regression analysis for variables predicting intentions } \\
to collaborate with science for sustainable community development (N=59) \\
\hline Variable & $\beta$ & SE $\beta$ & $\mathrm{B}$ & $\mathrm{R}^{2}$ & $P$-value \\
\hline Step 1 (Covariates) & & & & .07 & \\
Scientist or Native American group & -.31 & .28 & -.17 & .29 \\
Gender & -.18 & .23 & -.12 & .45 \\
Membership in organized religion & -.42 & .26 & -.25 & $.12^{\dagger}$ \\
\hline Step 2 & & & & .15 & \\
Identification with science & .001 & .10 & .001 & .96 \\
Individualism & .15 & .08 & .29 & $.08^{*}$ \\
Human goodness & .05 & .11 & .07 & .69 \\
Mastery over nature & -.04 & .12 & -.06 & .74 \\
Present-to-future time-orientation & .10 & .11 & .14 & .37 \\
\hline Step 3 & & & & .28 & \\
Positive attitude toward science (pATS) & .42 & .18 & .47 & $.02 * *$ \\
Negative attitude toward science (nATS) & .22 & .17 & .28 & .21 \\
\hline
\end{tabular}


Note: In step $1, \mathrm{R}^{2}=.07(p=.42), \mathrm{R}^{2} \Delta=.09(p=.42)$ in step $2, \mathrm{R}^{2} \Delta=.12(p=.06)$ in step 3. * $p<$ $.10, * * p<.05, \dagger p<.15$ (marginal significance).

Table 2. Full model summary of hierarchical regression analysis for variables predicting intentions to perform science-related sustainable Native community development action plans. Variance explained at each step is included.

\section{General positive Attitudes toward Science (pATS) and negative Attitudes}

toward Science (nATS). Based on the literature that science and Native cultures differed in values, coupled with the adverse historical and contemporary consequences of technology for Native people, I hypothesized that Native Americans would have less pATS (hypothesis 4) and more nATS (H5) than scientists. I tested this using a $2 \times 2$ MANCOVA with cultural group (scientist v Native) and gender (male v female) as independent variables. Membership in an organized religion was used as a covariate. Multivariate analyses showed a statistically significant difference between scientists' and Native Americans' ATS, $F(2,47)=4.90, p=.01, \eta^{2}=.17$. Neither gender, $F(2,47)=.15, p$ $=.87, \eta^{2}=.006$, nor its interaction with scientist/NA group was significant, $F(2,47)=1.08$, $p=.35, \eta^{2}=.04$

Univariate tests showed that differences between scientists and Native Americans were driven by ratings on nATS. Positive attitudes toward science did not differ between scientists and Native Americans, $F(1,48)=.19, p=.66, \eta^{2}=.004$, failing to support hypothesis 4 . In support of hypothesis 5 , Native Americans $(M=4.75, \mathrm{SD}=.28)$ endorsed negative attitudes significantly more than scientists $(M=3.84, \mathrm{SD}=.15), F(1$, $48)=6.56, p=.006, \eta^{2}=.15$. The correlation between pATS and nATS $(r=-.55, p<$ .001) was in similar size and direction as national estimates throughout the US and Canada ( $r=-.60$; Miller, 2004). 
Cultural values. Psychological and science education literature described apparent differences in values between science and Native cultures, however, arguments were conceptual rather than empirically-based. I therefore hypothesized differences between scientists and Native American on four cultural values; individualism (hypothesis 6), the belief in human goodness (H7), the belief that humans should master nature (H8), and future time-orientation (H9). I tested these hypotheses using a 2x2 factorial MANCOVA. I entered group membership (scientist v Native) and gender (male $\mathrm{v}$ female) as independent variables and membership in an organized religion as a covariate. Multivariate analyses revealed no significant effects for scientist/NA group, $F(4,45)=1.20, p=.32, \eta^{2}=.10$, or gender, $F(4,45)=.68, p=.61, \eta^{2}=.06$. The interaction between scientist/NA group and gender was also non-significant, $F(4,45)=$ $.65, p=.63, \eta^{2}=.06$

In partial support of hypothesis 8, scientists and Native American's differed on the belief that humans should have mastery over nature with marginal significance in univariate tests, $F(1,48)=2.50, p=.12, \eta^{2}=.05$. Scientists $(M=2.57, \mathrm{SD}=.16)$ agreed that humans should master nature marginally significantly more than Native Americans $(M=2.01, \mathrm{SD}=.31)$. No other comparisons or interactions were significant, lending no statistical support for hypotheses predicting differences in other cultural values.

Significant differences were not found to support hypotheses 6 (individualism), 7 (goodness), or 9 (future orientation). Contrary to hypotheses, though not statistically significant, scientists $(M=4.35, \mathrm{SD}=.23)$ were nearly equal on individualism with Native Americans $(M=4.36, \mathrm{SD}=.44)$ and scientists $(M=5.80, \mathrm{SD}=.18)$ believed in 
human goodness more than Native Americans $(M=5.48, \mathrm{SD}=.34)$. As expected, scientists were more future time-oriented $(M=5.34, \mathrm{SD}=.16)$ than the Native Americans $(M=4.94, \mathrm{SD}=.31)$, though this did not reach statistical significance.

Beliefs about science. Psychological and historical literature describes Native Americans as having current and historically negative experiences with science and technological development in mainstream society. In hypotheses 10-16, I predicted differences between scientists and Native Americans on seven beliefs about science; identification with science (hypothesis 10), economic advantage (H11), capability enhancement $(\mathrm{H} 12)$, prestige $(\mathrm{H} 13)$, traditionalism $(\mathrm{H} 14)$, social damage $(\mathrm{H} 15)$, and environmental damage (H16). I tested these hypotheses using a $2 \times 2$ factorial MANCOVA. I entered group membership (scientist v Native) and gender (male v female) as independent variables and membership in an organized religion as a covariate. Multivariate analyses showed a significant effect across beliefs about science and technology by scientist/NA grouping, $F(7,42)=2.10, p=.07, \eta^{2}=.26$. Gender distinction did not yield a significant difference, $F(7,42)=.84, p=.56, \eta^{2}=.12$. The interaction between scientist/NA grouping and gender was also not significant, $F(7,42)=$ $1.07, p=.40, \eta^{2}=.15$

Univariate tests revealed significant differences in identification with science by gender, $F(1,48)=4.62, p=.04, \eta^{2}=.09$. Males $(M=4.17, \mathrm{SD}=.35)$ identified with science significantly more than females $(M=3.25, \mathrm{SD}=.26)$. While these findings are in line with gender research on ATS, they do not support hypothesis 10 . Contrary to 
hypotheses, although non-significant, scientists $(M=3.58, \mathrm{SD}=.20)$ identified with science less than Native Americans $(M=3.83, \mathrm{SD}=.38)$.

The beliefs that science and technology offer economic advantage (hypothesis $11), F(1,48)=1.20, p=.27, \eta^{2}=.03$, and enhances human capabilities $(\mathrm{H} 12), F(1,48)=$ $.16, p=.65, \eta^{2}=.004$, were not significantly different between Natives and scientists in univariate tests, failing to support hypotheses 11 and 12. Average ratings of belief in economic advantage were higher for scientists $(M=4.62, \mathrm{SD}=.16)$ than for Natives $(M$ $=4.23, \mathrm{SD}=.31$ ), though the difference was non-significant. Contrary to expectations, although non-significant, Native Americans $(M=4.41, \mathrm{SD}=.27)$ rated the belief that science enhances human capabilities more than scientists $(M=4.27, \mathrm{SD}=.14)$.

In partial support of hypothesis 11 , however, a marginally significant interaction between scientist/NA group and gender on economic advantage, $F(1,48)=2.31, \mathrm{p}=.125$, $\eta^{2}=.05$, showed that differences were present among male participants. Females were similar whether they were scientists $(M=4.37, \mathrm{SD}=.19)$ or Native $(M=4.52, \mathrm{SD}=.37)$, whereas male scientists $(M=4.86, \mathrm{SD}=.26)$ reported more belief in economic advantage than Native males $(M=3.94, \mathrm{SD}=.49)($ see Figure 3$)$. 
Interaction between cultural group and gender on the belief that science and

technology provide economic advantage

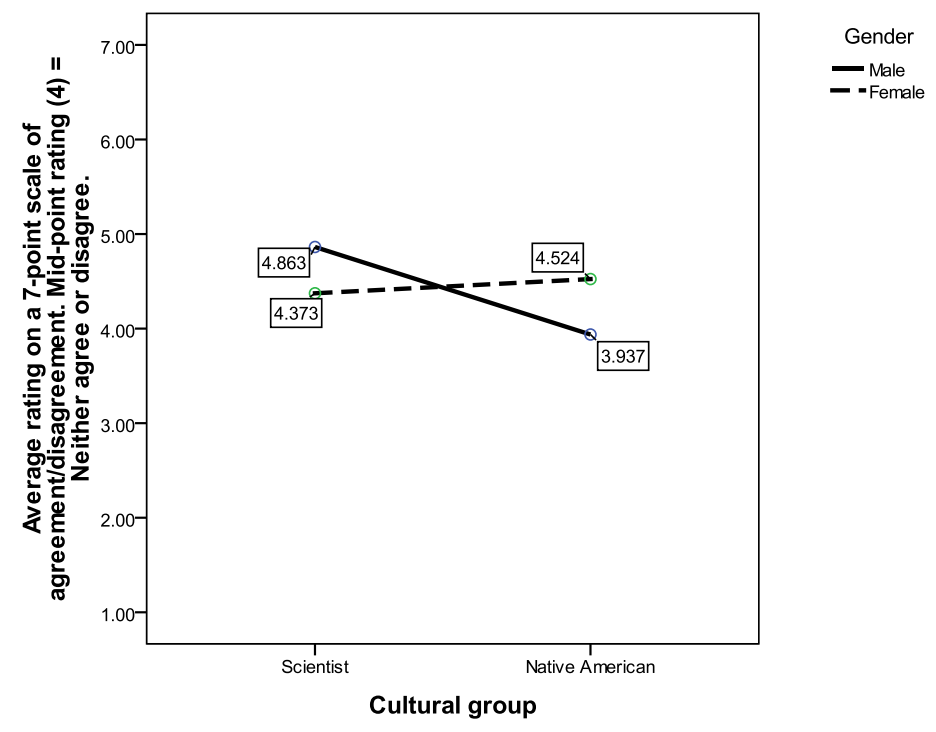

Figure 3. Interaction between cultural group and gender on the belief that science and technology provide economic advantage $(p=.13)$.

Univariate tests showed that scientists and Natives significantly differed in their belief that careers in science bring prestige $(\mathrm{H} 13), F(1,48)=.2 .04, p=.08, \eta^{2}=.06$. However, the difference was not in the expected direction. Scientists $(M=3.81, \mathrm{SD}=$ .13) believed that careers in science offer prestige significantly less than Native Americans $(M=4.32, \mathrm{SD}=.25)$, contrary to hypothesis 13 .

Scientists and Native Americans significantly differed on all of the negative evaluative beliefs in univariate analyses: traditionalism (hypothesis 14 ), $F(1,48)=6.80, p$ $=.01, \eta^{2}=.12$, social damage $(\mathrm{H} 15), F(1,48)=6.87, p=.01, \eta^{2}=.13$, and environmental damage $(\mathrm{H} 16), F(1,48)=6.84, p=.01, \eta^{2}=.13$. Native Americans $(M=4.77, \mathrm{SD}=.26)$ rated higher on traditionalism than scientists $(M=3.99, \mathrm{SD}=.14)$ in support of hypothesis 14. Native Americans believed that science and technology cause social 
damage $(M=4.93, \mathrm{SD}=.27)$ and environmental damage $(M=4.55, \mathrm{SD}=.39)$ more than scientists $(M=4.13, \mathrm{SD}=.14 ; M=3.41, \mathrm{SD}=.39)$ in support of hypothesis 15 and 16 .

A significant interaction between scientist/NA group and gender on social damage, $F(1,46)=2.65, \mathrm{p}=.07, \eta^{2}=.07$, reveals a caveat in support of hypothesis 15 , in that the difference between scientists and Natives is driven by males (see Figure 4).

Female scientists $(M=4.37, \mathrm{SD}=.17)$ and female Natives $(M=4.60, \mathrm{SD}=.33)$ report similar means regardless of group, while males answer quite differently depending on whether one is a scientist $(M=3.88, \mathrm{SD}=.23)$ or Native $(M=5.26, \mathrm{SD}=.43)$.

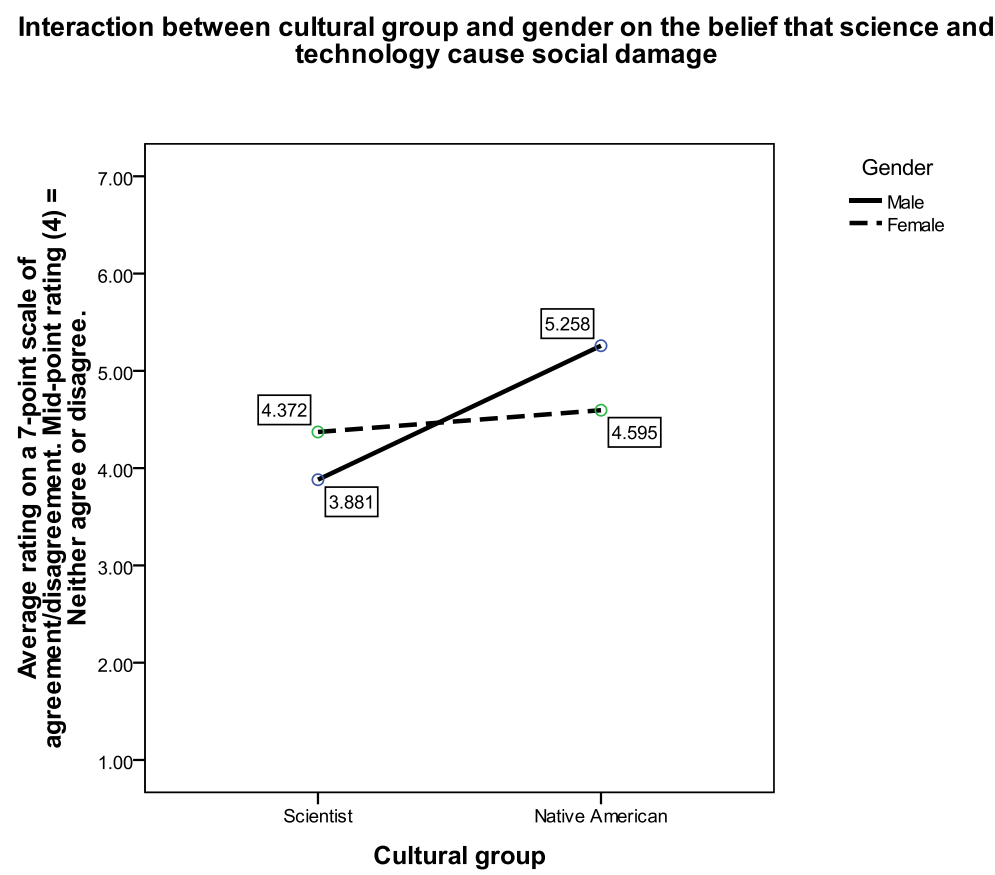

Figure 4: Interaction between cultural group and gender on the belief that science and technology cause social damage $(p=.07)$. 


\section{Discussion}

Future economic growth requires a higher proportion of people skilled in science, technology, engineering, and math (STEM) disciplines (Augustine, 2005). For growth that is also socially and environmentally sustainable, a ubiquitous increase in scientific knowledge and skills is centerpiece (World's Scientific Academies, 2000). In America, Native Americans have been disproportionately underrepresented in science education and careers, despite national and international requests for indigenous nations to collaborate in evidence-based sustainability planning (Executive, 2010; James, 2000; United Nations, 1992).

Reluctance to pursue science education or science-related information and activities has been attributed to a decrease in positive (or increase in negative) attitudes toward science (ATS; Osborne, Simon \& Collins, 2003). To extend ATS research and explore how ATS might potentially affect participation in sustainability planning with Native communities, I examined 1) how ATS, cultural values, and self-efficacy in science affect intentions to participate in science-related sustainability actions for Native communities, and 2) the possibility that Native Americans held collective attitudes toward science that were contrary to the science community's attitudes toward science.

Literature concerning Native Americans and their experiences with science education and technological progress suggested additional hypotheses to consider in regard to Native participation in science or science-related sustainability: 3) differences in science and Native American cultural values, and 4) Native communities' negative beliefs about science, due to their sharing a disproportionate amount of development's negative 
consequences. I evaluated these claims as well. Given sample size restrictions and the exploratory nature of this study, results were considered significant at $\alpha=.05$ and .10 in order to increase power to find an effect. Marginal significance was set at $\alpha \leq .15$.

ATS on sustainable action intentions. ATS research has been criticized for failing to use established theoretical frameworks within psychology to evaluate the ATS construct (Blalock et al., 2008; Pardo \& Calvo, 2002). At the same time, scientificallybased environmental research has sought ways to encourage participation from indigenous communities (Charnley, Fischer, \& Jones, 2007; Huntington, 2000). To contribute to both research needs, I examined the effect of ATS on intentions to participate in science-related sustainable development for Native communities using Ajzen’s (1991) Theory of Planned Behavior (TPB).

TPB outlines the connection between attitudes and behavior through intentions to behave, with normative beliefs and self-efficacy additionally predicting intentions (see Figure 1). I hypothesized that positive attitudes toward science (pATS; H1a), cultural values (i.e. normative beliefs; $\mathrm{H} 2 \mathrm{a}-\mathrm{d}$ ), and identification with science (i.e. self-efficacy to do science; H3) would predict an increase in intentions to act on science-related sustainable priorities for Native development. I also hypothesized that negative attitudes toward science (nATS) would predict a decrease in those intentions (H1b), as attitudes are described as essentially approach or avoidant affective cognitions (Albarracín, Johnson \& Zanna, 2005; Eagly \& Chaiken, 1993).

I examined the model using a hierarchical regression to examine the unique contribution of pATS and nATS. I entered the variables in steps of 1) relevant 
demographics (i.e. scientist/NA, gender, and membership in organized religion), 2) cultural values and identification with science, and finally, 3) pATS and nATS. The full model explained $28 \%$ of the variance in intentions with step 3 accounting for $12 \%$ of the total explained variance. Step 3 also resulted in significantly better fitting model than steps 1 or 2 . Positive attitudes toward science significantly predicted action intentions along with the cultural value of individualism. Results show that the ATS construct acts in accordance with established psychological theory and that pATS is an important motivator for sustainable planning. Limited evidence was found to support the use of cultural values as normative beliefs or identification with science as a measure of selfefficacy.

ATS. Research on attitudes in general, and attitudes toward science in particular, have neglected the cultural basis for attitude. In hypotheses $4-5$, I predicted that scientists and Native Americans would differ in their general positive attitudes toward science (pATS) and general negative attitudes toward science (nATS), where scientists would have more pATS (H4) and Natives would have more nATS (H5). These predictions were drawn from the psychological, historical, and science education literature that wrote that scientists and Native Americans participated in cultures that contained conflicting cultural values and that Native Americans had experienced more of science and technology's negative effects than other American cultural groups.

Multivariate analyses showed that scientists and Native Americans differ in their overall attitudes toward science. Contrary to hypothesis 4 , univariate tests revealed that general positive attitude toward science did not differ between scientist and Native 
groups. General negative attitude, though, did differ significantly, in line with hypothesis 5. Native Americans showed significantly higher negative attitude than scientists. There were no significant main effects for gender or its interaction with science/NA group membership. Support for hypothesis 5 advances research and theory on attitudes in support of a cultural, in-group basis for attitude formation. The differential impact of group membership on positive and negative attitudes shows the utility of treating general pATS and general nATS as separate constructs.

Cultural values. The psychological and science education literature describes cultural differences between scientists and Native Americans as a potential cause of underrepresentation of Native Americans in science careers (Aikenhead \& Ogawa, 2007; Cajete, 2000; James, Hiza, Hall \& Doppelt, 2008). Researchers, however, had not empirically evaluated the claim. I tested this across four universal cultural value continuums that were found to correlate with scores of Native American or Anglo identity among college and high school students (James, 2006), namely, individualism (H6), the belief in basic human goodness (v evil) (H7), that humans should master nature (v be at its mercy) (H8), and a preference for future (v present) time orientation (H9).

Scientists and Native Americans did not differ significantly on any of the cultural values I hypothesized in multivariate or univariate tests, failing to support hypotheses 69. Scientists did not differ from the Native Americans on individualism, human nature (evil v good), or time orientation (present $v$ future). Only the normative belief regarding humans' relationship with nature (at the mercy of nature v mastery over nature) approached significance (i.e., alpha $\geq .10$ ), with scientists endorsing mastery more than 
Native Americans $(p=.12)$. There were no significant differences by gender or its interaction with scientist/NA group membership. This portion of the study, therefore, can only offer limited evidence regarding the cultural divide between scientists and Native Americans.

Beliefs about science. The psychological and historical literature described Native Americans as experiencing less of science and technology's benefits (e.g. jobs, electricity) while having felt a disproportionate amount of the adverse consequences that come with development (e.g. pollution, land appropriation; Brook, 1998; James, 2001; James, Hiza, Hall \& Doppelt, 2008; Lewis, 1995). I hypothesized that these experiences would translate into lower identification with science (H10), lesser positive beliefs, and greater negative beliefs about science and technology compared to scientists. Positive beliefs about science and technology were that they provide economic advantage (H11), enhance human capabilities (H12), and that science careers offer prestige (H13). Negative beliefs about science and technology included traditionalism (H14), or the preference for old ways versus new technologies and the beliefs that science and technology cause social damage (H15) and environmental damage (H16).

Multivariate analyses showed that scientists and Native Americans significantly differed on their overall beliefs about science and technology. This was expected as six of the seven beliefs included in this analysis, excluding identification with science, were included in the attitudinal composites used to test difference in attitudes toward science. There were no multivariate differences for gender or its interaction with scientist/Native group. 
Identification with science did not significantly differ between scientists and Native Americans. This may have been because the item on race-based identification with science was dropped from the composite to maintain sufficient internal agreement. To test this possibility I re-ran the analysis with race-based identification as the dependent variable. Scientists and Natives still did not significantly differ although mean differences were in the expected direction. Supplementary analyses indicated that this non-significance was (at least partially) due to the presence of non-Caucasians among scientists. A comparison of three racial categories (Caucasian, Native American, and Other) showed that Caucasians identify with science significantly more than members of the other two groups. Native Americans were close to the mid-point of the rating scale while members of the "other" category were on the negative end of rated identification with science (i.e. they disagreed their ethnic group was good at developing new technologies).

While this is evidence that Native Americans identify with science less than Caucasians, it points to an even lower identification for other races. This was true despite the fact that those in the racially "other" classification had undergone science training. This is partial support for hypothesis 10 , in that Natives identified with science significantly less from Caucasian scientists. Unlike the sample in James and Cardador (2007), there was an insufficient number of African Americans, Latinos, or Asian Americans $(n=6)$ to evaluate identification beyond Caucasian and Native races, making for a weak test of ethnic/racial differences on the CABATS. About half of those in the "other" category described above were minorities underrepresented in science, 
technology, engineering, and mathematics (STEM), two were Asian, three were unidentified.

Unvariate tests identified that identification with science significantly differed by gender. Men rated their gender as responsible for technological achievements more than women. This was true despite the fact that the majority of the sample was female and scientist. Although no hypotheses were made in regard to gender this finding is in line with expectations from past research that has recognized a gender bias in science favoring males (James \& Cardador, 2007; NSF, 2011; Osborne, Simon, \& Collins, 2003, Simon, 2010; Task Force, 1989).

No significant univariate differences were found between scientists and Natives for either the positive belief that science and technology offer economic advantage or enhance human capabilities, failing to support hypothesis 11 and 12. However, in partial support of hypothesis 11, a marginally significant interaction between group and gender was found for economic advantage. Females rated the belief that science offers economic advantage similarly regardless of science/NA grouping, while Native males agreed with the belief less than male scientists. Scientists and Native Americans did significantly differ on the belief that careers in science offer prestige, but in the opposite direction to what I hypothesized, failing to support hypothesis 13. Native Americans believed that careers in science offer prestige more than scientists.

In support of hypotheses 14-16, scientists and Native Americans significantly differed on all three of the negative beliefs about science and technology in the expected direction. Native Americans were significantly higher in their traditionalist sentiments 
and beliefs that science and technology cause social and environmental damage.

However, a significant interaction between scientist/NA group and gender on the belief that science causes social damage shows that the difference in this belief is driven my males. Females rated the belief that science causes social damage similarly across groups while Native males endorsed the belief that science causes social damage more than male scientists.

\section{Implications}

This study contributes to two dialogues related to public participation in scientific and technological endeavors. The first pertains to theory and research on attitudes toward science (ATS), in terms of addressing past criticisms, identifying new antecedents, and examining its relevance for sustainability. The second pertains to Native American's underrepresentation in science, technology, engineering, and math (STEM) education/careers.

ATS. Past ATS research has been criticized for 1) often using unvalidated measures of attitudes and 2) lacking a theoretical foundation (Blalock et al., 2008; Osborne, Simon, \& Collins, 2003; Pardo \& Calvo, 2002). Blalock et al. (2008) argued that without validated measures and a theoretical foundation, we cannot be sure what we measure is really "attitudes toward science" and that any predictions we make with our construct are problematic. By utilizing James and Cardador's (2007) Cognitions and Beliefs about Technology and Science (CABATS) inventory and employing traditional definitions of attitudes in psychology as comprising positive and negative beliefs (Kronisk, Judd, \& Wittenbrink, 2005), I was able to conduct analyses with some 
confidence in the construct's reliability. I answered Blalock et al.'s (2008) criticism as attitudes were not the composites of haphazardly produced single-item measures, but rather derived from a validated inventory using conventional methods of calculation from psychology theory (e.g. Anderson \& Fishbein, 1965; Likert, 1932; Osgood, Suci \& Tannenbaum, 1957).

Once having calculated composites of ATS from instruments with known psychometric properties, an adapted form of Ajzen's (1991) Theory of Planned Behavior (TPB) made it possible to tie ATS into the broader context of attitude research in psychology. My findings suggest that ATS behaves as it should according to attitudinal theory, in that positive attitudes toward science, along with the cultural value of individualism, predict an increase in science-related behavioral intentions. This finding supports the idea that ATS is a legitimate construct showing some predictive validity.

Given the context of my research, the application of Ajzen's model also helped assess ATS' potential impact on the contemporary issue of inter-cultural sustainability planning. I showed that some specific attitudes towards science explain a significant amount of the variance in intentions to act for science-related sustainable Native community development (e.g. scientific skill development, conflict resolution between scientists and Natives); while general positive attitude predicts an increase in intention to perform those actions. To boost participation in our current conception of sustainability, it may be necessary to also promote positive attitudes toward science. This finding is important to ATS research as it treats ATS as a predictor, rather than an outcome, and demonstrates the usefulness of programs designed to increase positive ATS. 
If ATS can continue to be shown to predict of intentions to participate in science activities, and perhaps science education and occupations, measurement of ATS might also serve as a selection tool or subject of a training exercise for science-based jobs and programs (Morgeson \& Dierdorff, 2010). Positive attitudes toward science might relate with motivation and efficacy as an essential component of the "other" characteristics in science fields required knowledge, skills, abilities, and other characteristics (KSAO's). This is important not only for current job selection but also education or pre-employment programs designed to equip future students and employees or address declines in American science majors.

Through comparative analyses, I found significant differences between scientists' and Native American's negative attitudes toward science. This finding is in support of the idea that attitudes, in general and toward science in particular, can be based on culturally defined in-group perceptions and experiences. This is an important extension of current ATS theory.

Three decades of focusing on the "deficit model" in ATS research attributed individual-level ignorance of scientific facts and methods as the predominant cause of negative attitude toward science (Sturgis \& Allum, 2004). Other research has examined distal factors on ATS, such as country-level industrialization (Bauer, Durant \& Evans, 1994) or popular media portrayals (Jensen \& Hurley, 2010), as well as proximal factors, such as gender (Simon, 2010; Park, Young, Troisi \& Pinkus, 2011), education (Gibson \& Chase, 2002; Papanastasiou \& Papanastasiou, 2004), personal relevance (Connor \& Siegrist, 2010; James, 1993) and competitive values (Critchley, 2008; Ellison \& Musick, 
1995). According to the literature that guided my predictions, Native Americans' attitudes toward science might be shaped partly by their historical and on-going negative experiences with mainstream development. Research comparing different cultural groups' beliefs and attitudes toward science should consider the historical and contemporary contexts through which those groups encountered science and technology as a mediator of cultural group membership and attitudes toward science.

Underrepresentation. Underrepresentation of Native Americans in science education and careers has been attributed to two different causes. The first is that Native cultural values differ from those propagated in science (Aikenhead \& Ogawa, 2007; James, Hiza, Hall \& Doppelt, 2008). The second is that Native American's communitylevel experiences, historical and current, have felt more of science and technology's adverse effects, and less of their benefits, than any other (North American) group (James, 2000; Lewis, 1995).

Little evidence was found for the differences in cultural values. Specifically, my analysis on cultural values was only able to offer marginally significant evidence for one of the four values I tested. Scientists believed that humans should master nature marginally significantly more than Native Americans. Future research should further investigate how this cultural value might differ between these groups and how the belief that humans should master nature influences scientific applications, or, in other words, the extent to which scientific research and practice is motivated by the belief that humans dominate nature. It is possible that Native underrepresentation in science is partly due to 
the way scientific study objectifies nature, in contrast to Native cultures' personification of Mother Earth.

One the other hand, negative attitude toward science, and the beliefs that comprise it, were shown to differ significantly between scientists and Natives. Native Americans held negative beliefs about and negative attitude toward science significantly more than scientists. Analyses at the level of specific beliefs (as opposed to general attitude) revealed that social and environmental damage are significant elements of Native American attitudes toward science. Given Native American's historical and current experiences with development, evidence of these beliefs changes the focus of any purposed intervention to address underrepresentation of indigenous groups. Had I only compared scientists and Natives at the attitudinal level, it would have been easy to envision an intervention that tried to remedy Native attitudes. Analyses at the belief level, however, make it clear that their attitudes may reflect a genuine criticism of science and development. The fuller understanding made possible through different levels of analysis (i.e. general attitudes and specific beliefs) shows the flexibility of the CABATS (James \& Cardador, 2007).

It is interesting and unexpected that no difference was found for positive attitudes toward science, and when differences were found for a positive belief that Natives rated it higher than scientists. This suggests that Native underrepresentation is probably more due to their negative experiences rather than a failure to see the benefits of science. If it is true that Natives and science differ on cultural values related to the treatment of the ecosystem, underrepresentation may be viewed as a boycott rather than a problem of 
perspective. Comparable with the reforms in social-behavioral research in light of injustices perpetrated on Native Americans (Hodge, 2012), perhaps alternative paradigms in the physical, life, and technological sciences could change the trajectory of environmentally reckless innovation and, by proxy, beliefs and attitudes about science.

In line with this reasoning, an intervention on Native attitudes toward science may need to start with science itself. It is through scientifically achieved means of natural resource extraction, consumption, and pollution that we have found ourselves in a globally unsustainable lifestyle (Fowler \& Hobbs, 2003). Sustainability advocates have already called upon scientists to begin thinking in terms of interdisciplinary and dynamic systems, rather than as decontextualized silos, in order to consider the ramifications of our discoveries' applications on other natural and human systems (Fiksel, 2006). Research on the delivery of science curriculum aimed at Native students should include curricula that genuinely incorporate indigenous environmental and human ethics. Likewise, invitations to collaborate in research activities (e.g. TEK) should include additional steps to incorporate concerns and safeguard Native communities from unintended negative consequences.

\section{Applications}

This study was designed to evaluate the effect of attitudes toward science on sustainable Native community development and to explore potential influences on Native American participation in science. Although the findings have implications for theory and research in minority education and attitudes toward science, in general, they can also be 
applied to current recruitment practices for Native Americans in STEM education and careers and inter-cultural collaborations for sustainable development.

Firstly, it is notable that scientists and Native Americans differed on negative attitude toward science and not positive attitude toward science. Negative attitude comprised the beliefs that old ways are preferable to new technologies (traditionalism) and that science and technology caused social and environmental damage. Positive attitudes comprised the beliefs that science and technology increase human capabilities and offer economic advantages. In the case of Native Americans as an underrepresented minority, promoting positive attitudes toward science may be less useful than alleviating negative attitudes.

Given the negative beliefs included in my attitudinal composite, decreasing negative attitudes might include a more equitable share of technological benefits in Native communities (e.g. health services) or the creation of innovative ways that Native communities can maintain their traditional ways more effectively with the use of science and technology. The creation of innovative ways to maintain culture might reverse the historical trend of science serving mainstream interests and instead validate the scientific and pro-environmental qualities of traditional belief systems (Cajete, 2000; Cristancho \& Vining, 2004).

This approach is already being practiced by some educational institutions and has even been adopted by some indigenous communities. One example is the Associates in Science program at Hawaii's Kapiolani Community College. Traditional science curriculum is taught within the context of natural habitat preservation and involves 
Hawaiian Native students' families and cultural leaders. The program synergizes the goals of the federal government to increase participation in science with the needs of indigenous communities to maintain the access to, and availability of, culturally significant natural resources. Another example is the video library held at the Australian Institute for Aboriginal and Torres Strait Islander Studies (AIATSIS). Together with a movement among indigenous communities, AIATSIS aids the preservation of Aboriginal language and culture through documentaries that are regulated by cultural protocols. Research on these and other constructive uses for science and technology within indigenous communities should evaluate their effect on ATS.

A more equitable share of science and technology's benefits in Native communities may also attenuate some of the obstacles to higher education facing Native youth. Poor social and economic conditions have been argued to contribute to the lack of adequate college preparation. If science and technology do in fact offer economic advantages, within a few generations it may be possible to address some the crippling poverty, health problems, and lack of infrastructure that plague many Native families and communities on and off reservations (James, 2000; James, Wolf, Lovato, \& Byers, 1995; Ogunwale, 2002).

Another possible route for utilizing my findings to boost Native participation in science is through identification with science. The results make it seem as though Natives have positive views of science, but simply do not believe they belong in science or share in its positive ramifications. This might be addressed by culturally inclusive curriculum (Pan, 2006), hiring more Native teachers (James, Chavez, Beauvais, Edwards, \& Oetting, 
1995), including family and community in the education process (Guillory \& Wolverton, 2008) or, presumably, by providing more and better collaborative experiences with nonNative scientists. The potential effects of such interventions on identification with, and beliefs about, science should be tested in future studies.

Some case study evidence suggests that culturally inclusive education can lead to successful performance in science-related fields. Small or specific (e.g. Navajo) groups of Native students have been shown to do well in science when a cultural framework is employed (Semken \& Morgan, 1997), to complete medical school when tribal connections and spirituality are maintained (Hollow et al., 2004) and to benefit from the inclusion of tribal elder support in a nurse-scientist training program (Moss, et al., 2005). Qualitative research has demonstrated positive intercultural experiences between students and faculty (Brandt, 2008) and developing an Indian academic identity (Montgomery, et al., 2000) or a dual identity (Brayboy, 2004) aids adjustment to non-Native educational settings. Strong Native student performance has also been shown to relate with a higher number of white friends (Kerbo, 1981) and from higher self-esteem in general (Whiteshell, et al. 2009). The antecedents of, and interventions designed to promote, possible bi-cultural and dual-identity mediators of NA science outcomes should also be looked at in future studies.

According to self-identity theory (Tajfel, 1978, 1982, Tajfel \& Turner, 1979), individuals align their behavior with the behaviors of their immediate group (e.g. family) as well as their collective in-group (e.g. social category). When it is impossible to achieve a positive sense of self, an individual (or a community among communities) can 
disparage the majority standard and create new dimensions of comparison. It is possible that Native scientists experience a pull from their dual membership in opposite directions. It would be interesting to know how Natives (as individuals or as a group among nonNatives) create identities for themselves that meet expectations in both Native and science circles, or how virtues in one are disparaged over virtues in the other (see, e.g. James, 2006). It would also be interesting to see how these tensions vary by cohort (e.g., age groups), especially as cultural competence in the classroom and workplace and the availability of cultural-inclusive science programs increase.

In accord with results of some previous studies, the gender results here also support identification with science as important for groups other than Native Americans. Science has continually resurfaced in the literature as a stereotypically 'masculine' endeavor for an assortment of reasons, ranging from biology to socialization to sociocultural constraints (for a review, see Ceci, Williams, \& Barnett, 2009 and Osborne, Simon \& Collins, 2003). Despite evidence that no substantial differences exist in terms of ability, women consistently avoid graduate level science degrees and professions (Hyde \& Linn, 2009), hold negative attitudes toward science (Simon, 2010), and identify less with science than men (James \& Cardador, 2007).

Results from analyses on identification with science suggest that science education and pre-employment training programs should work to increase identification with science for minorities and women. This might be addressed by taking action to reduce stereotypes about these groups. Identification with science has been shown to increase persistence within science fields while negative race-based college experiences 
have been shown to influence switching from science to non-science majors for Black and Native American students (Chang, Eagan, Lin, \& Hurtado, 2011). In a double-blind study of both male and female faculty at science universities, faculty job applications were rated lower for female applicants despite having matched (identical) resumes with male applicants (Moss-Racusin et al., 2012). Such biases could contribute student's feelings of self-efficacy within science fields (Eccles, 1993) and reduce the number of female and minority teachers and faculty role models available to reach underrepresented students. Future research should further examine the effect of racial and gender biases within the science community on student achievement and progression into science careers.

The findings from this study also have implications for collaborations for community sustainability. The current study showed that positive attitude toward science predicts an increase in intentions to engage in science-related sustainable action. This finding vindicates research that has sought to identify factors that lead to increases in positive attitudes toward science (e.g. Gibson \& Chase, 2002; James, 1993;

Papanastasiou \& Papanastasiou, 2004). Efforts in research, policy, and education should continue to identify factors and conditions that increase the positive beliefs about science and technology. Popular media might also incorporate the finding that positive attitudes toward science increase intentions to participate in science activities by emphasizing the practical benefits to individuals and societies who excel in science (e.g. The History Channel's "Engineering an Empire” series).

\section{Limitations and future directions}


The most serious limitation to this study was its sample size. Sample size hindered my power to find effects and therefore, the reliability of my findings. For example, Tabachnick and Fidell (2007, p.123) recommend a sample size of $\mathrm{N} \geq 104$ plus the number of predictors for any regression analysis where interpreting individual predictors is important. Clearly, then, the sample size obtained here was undesirably small. Future studies should work to recruit larger samples to increase power and allow for more comparisons, especially between underrepresented ethnic/racial groups I was not able to evaluate here.

Comparisons I made between scientists and Native Americans also suffered from self-selection and, consequently, non-representativeness of the populations of interest. Evidence of these concerns can be seen in that the Native American participants in my sample did not differ in their levels of education from scientists. Native Americans have not attained education comparable to the general population according to census estimates (Ogunwale, 2006). This disparity is no doubt exaggerated between Native Americans and the science community. Educated Natives however seemed apparently more likely to participate in collaborative activities with scientists. To develop successful community planning, research must involve a broader range of representatives. As is, it is not possible to tease apart the influences of Native culture from educational experiences. It is possible that non-science education, or the motivation for non-science education, is related to higher negative attitude toward science.

For example, in 2012 I conducted a preliminary study where I interviewed six Native Americans who had attained bachelor degrees (or higher) in science versus non- 
science disciplines. Participants were asked to tell their story regarding how they came to decide their major followed by questions about beliefs and attitudes toward science. The interviews were analyzed using classical content analysis with Bronfenbrenner's and Morris's (1998) ecological systems theory to guide counts of relevant micro, meso, and exosystem influences mentioned in participants' stories. Positive beliefs and attitudes toward science were similar between groups based on degree major. Negative attitudes, however, were different between science and non-science majors, where non-science majors reported more negative beliefs and attitude toward science. This finding was similar to the results of the current study involving non-Native scientists and educated non-scientist Native Americans. These findings together suggest that either science education reduces negative attitude toward science or a non-science education promotes negative attitudes toward science. However, looking at the proximal processes identified by Bronfenbrenner and Morris (1998) I found that non-science majors also reported higher incidences of difficult early school experiences, lesser availability of adequately funded programs, fewer supportive social networks, less academic encouragement from family, teachers, and friends, more problems in their surrounding community, and more ethnic identity. From the limited data I concluded that one's choice of major was motivated by their life experiences, where positive experiences lead one to consider career choices through education (science majors) and negative experiences lead one to consider addressing community need through education (non-science majors). Whether differences in beliefs and attitudes toward science were caused by type of degree or one's life experiences could not be ascertained. What does seem clear is that Natives tend to 
hold positive attitude toward science. The source of negative attitudes, however, requires future studies to sample a fuller range of educational backgrounds and life experiences to control for the confounding effect of education and more accurately represent the Native population.

The science sample in this study also suffered from self-selection. For instance, there was an unexpectedly high proportion of females in the science group (65\%); given that women only comprise $27 \%$ of U.S. scientists (NSF, 2011, see table $9.5^{8}$ ). This nonrepresentativeness limits the generalizability of this study. On the other hand, there are two advantages to the obtained science sample. First, similar to the overrepresentation of educated Natives, it is possible that this sample represents the current factions of science that are most willing to collaborate with Natives. If this is the case, my results are relevant to current collaborators. Second, non-representativeness is most threatening when the independent variables are thought to act differently because of some unique selection-grouping effect.

In this study, non-representativeness suggests a reduction in power to find an effect, as groups consisting of female scientists and educated Natives are presumably less different than male scientists and the general Native population. For example, both women and Natives are underrepresented in science (NSF, 2011) and movements exist for each group to revamp science of its Caucasian male orientation (Cajete, 2000; Chambers \& Gillespie, 2000; Johnson \& Murton, 2007; Ussher, 1999). Additionally, all of the participants in this study had been invited to attend community planning

\footnotetext{
${ }^{8}$ TABLE 9.5: Employed scientists and engineers, by occupation, highest degree level, and sex: 2008. From http://www.nsf.gov/statistics/wmpd/pdf/tab9-5.pdf.
} 
workshops involving an indigenous framework on the basis of prior involvement and interest. Therefore the sample composition attenuates differences in more mainstream science and Native cultures. The fact that I did find significant differences suggests my findings are probably conservative estimates.

Sample size also affected the composition of sub-groups. One particular subgroup of important theoretical interest could not be evaluated here because of their insufficient number, i.e. Native scientists. With organizations such as the American Indian Science and Engineering Society facilitating movement from science education to science careers for Native students, the inability to evaluate this growing social category testifies to the concern that my estimates do not represent the full spectrum of the Native or science community. In this study, Native scientists seemed to more closely resemble non-Native scientists on their ratings of measures used here (see preliminary analyses). Whether or not this is caused by individual differences prior to science education or the socialization process that takes place during science education is open to further study. If socialization is the culprit perhaps that is another reason for Native American reluctance to pursue science degrees and careers despite their positive beliefs about the field.

Another limitation of this study was its operational definition of cultural values, positive beliefs about science, and behavioral intentions. Cultural values were measured using single and dual-item measures of Kluckhohn's (1950) purportedly universal cultural dimensions. Although the cultural dimensions have received empirical support (Kluckhohn \& Strodtbeck, 1961; Maznevski, et al., 2002), justification for item phrasing and previous reliability and validity evidence were not available for the scale utilized in 
this study. How well each item properly tapped into its cultural construct is debatable. Future studies should employ an instrument of cultural values with established psychometric quality and appropriate cross-cultural relevance.

The use of James and Cardador's (2007) Cognitions and Beliefs about Technology and Science (CABATS) inventory provided a more reliable tool for measuring positive and negative beliefs about science than most research on ATS. However, as described in the section on preliminary analyses, this sample produced problematic inter-item correlations for all three of the positive belief dimensions. It might be that an increase in sample size would resolve these issues, but perhaps a revision of positive belief dimensions reassessing item breadth or potential dimension facets should also be explored.

Another direction for future research with the CABATS should be to subject the inventory to confirmatory factor analyses (CFA) evaluating general positive and negative attitudes toward science. Consistent with past research on attitudes, positive and negative evaluative beliefs about science were averaged to create general attitudes. Although a preliminary principal components analysis supported this decision, the sample size did not support the use of CFA's which would have provided stronger empirical evidence of general attitudinal dimensions along with model fit indices. Future research should test the CABATS inventory's usefulness as a measure of general attitudes toward science.

Action priorities served as the dependent variable in my final analysis because of their function as intentions, given the sampling conditions. No prior reliability evidence or factor structure was available for the inventory and the sample size did not allow for 
confirmatory factor analysis. It is possible that attitudes and cultural values would have predicted priority sub-factors differently than a single composite score. In addition, since the rating items were developed by Native people, it is possible they do not cover the full breadth of sustainable community development priorities. Similarly, it is possible that negative attitude toward science did not predict a decrease in intentions to perform action priorities because science-related priorities also include science reform. Future research on scientific intentions for community sustainability should both employ larger samples that allow for confirmatory factor analyses of the inventory; and develop community action and research priorities rating items with a broader (i.e., beyond just NA's) range of participants.

The third limitation of this study was inability to test the full model of Ajzen's (1991) Theory of Planned Behavior (TPB). TPB prescribes predicting a particular behavior from intentions to perform that behavior; and predicting those intentions from attitudes toward, normative beliefs about, and self-efficacy to do that behavior. In this study only the component of TPB about attitudes predicting intentions was fully included. Specifically, the use of identification with science for self-efficacy, the (unsuccessful) use of broad cultural values rather than normative beliefs, and the lack of a behavioral outcome disqualify this study from being a full test of the TPB model (Armitage \& Conner, 2001). Future studies of science attitudes and science outcomes should incorporate the full TPB measures and model.

Fourthly, there were several practical choices and logistical obstacles that limited the veracity of this project's conclusions. For one, the survey was administered online. 
Online administration may have had the unfortunate consequence of discouraging participation from those without reliable access to the internet (most likely affecting Native community participants).

Participation may have been deterred due to the length of the survey. The full survey contained roughly one hundred questions. The only incentive offered for participation was to help plan for the workshop and aid science and Native community collaboration. This probably led to those who felt most strongly about the subject matter to complete the survey. Incentives, paper and pencil surveys, and reminders to complete surveys should all be included in future research.

Finally, with a sufficient sample size, the use of multilevel modeling should be considered to make it possible to test differences in ATS and its outcomes nested within geographical area, tribal nation, science discipline, data collection period, and administration type (paper/online). The degree to which, for instance, different participating tribal communities have been adversely affected by science and technology could be assessed (by, e.g., number acres ceded, preventable disease rates, pollution statistics, legal disputes involving science evidence) to observe if ATS changes with past and current experiences of the cultural in-group. Structural equation modeling could be used to model the relationships between cultural values, beliefs and attitudes toward science, and attitudinal outcomes for different groups simultaneously.

Another fruitful direction in ATS research would be to examine the drivers of scientist and Native's beliefs about science. How is it that a group communicates its beliefs and attitudes toward science to one another? Which symbols, community 
reactions, jokes, or stories encapsulate the perspective of Natives' attitudes toward science, and how do these change as Native youth continue through education? How does identity develop for a novel member in the science community? How does she create adaptive/maladaptive means of identity formation within multiple, sometimes opposing cultural contexts? Those are the types of questions that this line of research would examine.

Lastly, in accord with national and international calls to include indigenous perspectives in sustainable development, more research voices are needed on how to successfully integrate Native views into sustainability research and action (Huntington, 2002). Actions could include the before mentioned safeguards against validating Indigenous negative beliefs about science, conducting culturally-valued and communityrelevant research, and implementing culturally responsive curriculum (CRS; Castagno \& Brayboy, 2008). Refocusing our attention to the scientists, this could take the form of research on attitudes among scientists toward Traditional Ecological Knowledge (TEK), indigenous people, or the incorporation of indigenous culture and TEK into science education.

\section{Conclusion}

This project is only one step in our understanding of attitudes toward science and its relationship to culture. With the future of this planet in the balance, the significance of Native American and scientist attitudes toward science extends further than its economic prospects or merely encouraging more engineers. The idea of infinite scientific exploitation of nature toward infinite growth has been deemed unrealistic and dangerous 
(Fowler \& Hobbs, 2003; United Nations, 1987; 1992; 1997). We are in need of a paradigm shift (Kuhn, 1970); one that considers our interdependent relationship with all things living and not-living. The results of the current study, and the line of research that it is a part of, are steps in that direction. 


\section{References}

Aikenhead, G.S. \& Ogawa, M. (2007). Indigenous knowledge and science revisited. Cultural Studies of Science Education, 2, 539-620.

Ajzen, I. (1991). The theory of planned behavior. Organizational Behavior and Human Decision Processes, 50, 179-211.

Ajzen, I \& Fishbein, M. (2005). The influence of attitudes on behavior. In D. Albarracín, B. T. Johnson, \& M. P. Zanna (Eds.), The handbook of attitudes and attitude change (pp. 173-706). Erlbaum.

Ajzen, I \& Madden, T.J. (1986). Prediction of goal-directed behavior: Attitudes, intentions, and perceived behavioral control. Journal of Experimental Social Psychology, 22, 453-474.

Akpinar, E., Yildiz, E., Tata, N. \& Ergin, O. (2009). Students' attitudes toward science and technology: An investigation of gender, grade level, and academic achievement. Procedia Social and Behavioral Sciences, 1, 2804-2808.

Albarracín, D., Johnson, B. T., \& Zanna, M. P. (Eds.) (2005). The handbook of attitudes. Mahwah, NJ: Erlbaum.

Allum, N., Sturgis, P., Tabourazi, D. \& Brunton-Smith, I. (2008). Science knowledge and attitudes across cultures: A meta-analysis. Public Understanding of Science, 17, 3554.

Anderson, L.R. \& Fishbein, M. (1965). Prediction of attitude from the number, strength, and evaluative aspect of beliefs about the attitude object. Journal of Personality and Social Psychology, 2(3), 437-443. 
Angel, B. (1991). The toxic threat to Indian lands. A Greenpeace Report. Retrieved April 25, 2010 from http://www.ejnet.org/ej/toxicthreattoindianlands.pdf.

Armitage, C.J. \& Conner, M. (2001). Efficacy of the theory of planned behavior: A metaanalytic review. British Journal of Social Psychology, 40, 471-499.

Augustine, N.R. (2005). Rising above the gathering storm: Energizing and employing America for brighter economic future. $109^{\text {th }}$ Congress (First Session). Statement of Norman R. Augustine to U.S. House of Representatives, Committee on Science. Retrieved April 26, 2010 from http://www7.nationalacademies.org/ocga/ testimony/gathering_storm_energizing_and_employing_america2.asp

Augustine, N. R. (2007a). The Future of America's Workers and Education for the $21^{\text {st }}$ Century. $110^{\text {th }}$ Congress (First Session). Labor Health and Human Services Education and Related Agencies. Retrieved April 25, 2010 from http://www7.nationalacademies. org/ocga/testimony/Prospering_in_the_Global_Economy_of_the_2 $1^{\text {st }}$ _Century.asp

Augustine, N.R. (2007b). Rising above the gathering storm: Energizing and employing America for brighter economic future. National Academies Press: Washington, D.C. Retrieved December 10, 2011 from http://www.utsystem.edu/competitive /files/RAGS-fullreport.pdf

Bauer, M., Durant, J. and Evans, G. (1994). European Public Perceptions of Science. International Journal of Public Opinion Research, 6, 163-86.

Bauer, M.W., Petkova, K. \& Boyadjieva, P. (2000). Public knowledge of and attitude to science: Alternative measures that may end the "science war." Science, Technology, \& Human Values, 25(1), 30-51. 
Barben, D. (2010). Analyzing acceptance politics: Towards an epistemological shift in the public understanding of science and technology. Public Understanding of Science, 19(3), 274-292.

Berkes, F. (1999). Sacred ecology: Traditional ecological knowledge and resource management. Taylor and Francis, Philadelphia and London, UK.

Berkes, F., Colding, J. \& Folke, C. (2000). Rediscovery of traditional ecological knowledge as adaptive management. Ecological Applications, 10(5), 1251-1262.

Blalock, C.L., Lichtenstein, M.J., Owen, S., Pruski, L., Marshall, C. \& Toepperwein, M. (2008). In pursuit of validity: A comprehensive review of science attitude instruments 1935-2005. International Journal of Science Education, 30(7), 961-977.

Bodley, J.H. (1999). Victims of progress (4 ${ }^{\text {th }}$ ed.). Mayfield: Mountain View, CA.

Bohner, G. \& Dickel, N. (2011). Attitudes and attitude change. Annual Review of Psychology, 62, 391-417.

Bronfenbrenner, U. \& Morris, P.A. (1998). The ecology of developmental processes (Ch. 17). In the Handbook of Child Psychology ( $5^{\text {th }}$ ed.), 993-1028.

Bureau of Labor Statistics (BLS). (2009). News Release: Employment projections 20082012. U.S. Department of Labor. Retrieved December 12, 2011 from http://www.bls.gov/news.release/pdf/ecopro.pdf.

Bureau of Labor Statistics (BLS). 2010. Education pays.... U.S. Department of Labor, Retrieved September 8, 2011 from http://www.bls.gov/emp/ep_chart_001.htm.

Brandt, C.B. (2008). Discursive geographies in science: Space, identity, and scientific discourse among indigenous women in higher education. Cultural Studies of Science 
Education, 3, 703-730.

Brayboy, B.M.J. (2004). Hiding in the ivy: American Indian and visibility in elite educational settings. Harvard Educational Review, 74(2), 125-152.

Brayboy, B.M.J. \& Maughan, E. (2009). Indigenous knowledge and the story of the bean. Harvard Educational Review, 79(1), 1-21.

Brook, D. (1998). Environmental genocide: Native Americans and Toxic Waste. American Journal of Economics and Sociology, 57(1), 105-113.

Cajete, G. A. (1999). The Native American Learner and Bicultural Science Education. In Karen Cayton Swisher and John W. Tippeconnic III, (eds), Next Steps: Research and Practice to Advance Indian Education. Charleston, WV: ERIC Clearinghouse on Rural Education and Small Schools.

Cajete, G.A. (2000). Native science: Natural laws of interdependence. Santa Fe, NM: Clear Light Publishers.

Castagno, A.E. \& Brayboy, B.M.J. (2008). Cultural responsive schooling for Indigenous youth: A review of the literature. Review of Educational Research, 78(4), 941-993.

CBD Secretariat. (n.d.). Traditional knowledge and the convention on biological diversity. Retrieved June 5, 2011 from http://www.cbd.int/doc/publications/8jbrochure-en.pdf.

Ceci, S.J., Williams, W.M. \& Barnett, S.M. (2009). Women's underrepresentation in science: Sociocultural and biological considerations. Psychological Bulletin, 135(2), $218-261$.

Chambers, D.W. \& Gillespie, R. (2000). Locality in the history of science: Colonial 
science, technoscience, and Indigenous knowledge. Osiris, $2^{\text {nd }}$ Series, Vol. 15 , Nature and Empire: Science and the Colonial Enterprise, pp. 221-240.

Chang, M.J., Eagan, M.K, Lin, M.H, \& Hurtado, S. (2011). Considering the impact of racial stigmas and science identity: Persistence among biomedical and behavioral science. The Journal of Higher Education, 82(5), 564-596.

Charnley, S., Fischer, A.P., \& Jones, E.T. (2007). Integrating traditional and local ecological knowledge into forest biodiversity conservation in the Pacific Northwest. Forest Ecology and Management, 246, 14-28.

Connor, M. \& Siegrist, M. (2010). Factors influencing people's acceptance of gene technology: The role of knowledge, health expectations, naturalness, and social trust. Science communication, 32(4), 514-538.

Council on Environmental Quality. (2010). Climate Change Adaptation Task Force. Retrieved April 24, 2010, from http://www.whitehouse.gov/administration /eop/ceq/initiatives/adaptation

Cristancho, S. \& Vining, J. (2004). Reciprocity as principled argument: The ethics of human-nature interaction for the Letuama. Research in Human Ecology, 11(1), 36-50.

Cristancho, S. \& Vining, J. (2009). Perceived intergenerational differences in the transmission of Traditional Ecological Knowledge (TEK) in two indigenous groups from Colombia and Guatamala. Culture \& Psychology, 15(2), 229-254.

Critchley, C.R. (2008). Public opinion and trust in scientists: The role of the research context, and the perceived motivation of stem cell researchers. Public Understanding of Science, 17, 309-327. 
Diamond, J. (1999). Guns, germs, and steel: The fates of human societies. Norton \& Company: New York.

Eagly, A.H. \& Chaiken, S. (1993). The psychology of attitudes. Harcourt Brace Jovanovich College Publishers: Forth Worth, TX.

Energy Information Administration [EIA]. (2000). Energy consumption and renewable energy development potential on Indian Lands. U.S. Department of Energy: Washington, D.C.

Eccles, J.S. (1993). School and family effects on the ontogeny of children's interests, self perceptions, and activity choice. In Jacobs, J. (ed.) Nebraska Symposium on Motivation, 1992: Developmental Perspectives on Motivation, pp. 145-208. Lincoln: University of Nebraska Press.

Ellison, C.G. \& Musick, M.A. (1995). Conservative Protestantism and public opinion toward science. Review of Religious Research, 36(3), 245-262.

Executive Office of the President. (March, 6, 2010). Progress report of the Interagency Climate Change Adaption Task Force. Retrieved April 24, 2010 from http://www.whitehouse.gov/sites/default/files/microsites/ceq/20100315-interagencyadaptation-progress-report.pdf

Fact Sheet. (2010). Fact sheet on the President's clean energy radio address. Retrieved January 5, 2011 from http://www.whitehouse.gov/sites/default/files/ Fact_Sheet_weekly_address_100210.pdf

Festinger, L. (1954). A theory of social comparison processes. Human Relations, 7, 117 140. 
Fishbein, M. (1963). An investigation of the relationships between beliefs about an object and the attitude toward that object. Human Relations, 16, 233-239.

Fishbein, M \& Ajzen, I. (1975). Belief, attitude, intention and behavior: An introduction to theory and research. Reading, MA: Addison-Wesley.

Fiksel, J. (2006). Sustainability and resilience: Toward a systems approach.

Sustainability: Science, Practice, \& Policy, 2(2), 14-21.

Fleming, L., Engerman, K. \& Williams, D. (2006). Why students leave engineering: The unexpected bond. The American Society for Engineering Education. Retrieved April 25, 2010 from http://papers.asee.org/conferences/paper-view.cfm?id=863.

Fowler, C.W. \& Hobbs, L. (2003). Is Humanity Sustainable?. Proceeding of The Royal Society, 270, 2579-2583. Doi: 10.1098/rspb.2003.2553

Garcia-Quijano, C.G. (2008). Fishers' knowledge of marine species assemblages: Bridging between scientific and local ecological knowledge in Southeastern Puerto Rico. American Anthropologist, 109(3), 529-536.

Gardner, P. L. (1975). Attitudes to science. Studies in Science Education, 2, 1-41.

Garroutte, E.M. (1999). Getting serious about "interrogating representation.” Social Studies of Science, 29(6), 945-956.

General Accountability Office (GAO). (2005). Higher education: Federal science, technology, engineering, and mathematics programs and related trends. Report to the Chairman, Committee on Rules, House of Representatives. Retrieved December 10, 2011 from http://www.gao.gov/new.items/d06114.pdf

Gibson, H. L. \& Chase, C. (2002). Longitudinal impact of an inquiry-based science 
program on middle school students' attitudes toward science. Science Education $86(5)$

693-705.

The Global Compact. (2009). Global sustainability in the $21^{\text {st }}$ century: An action plan for business. Retrieved April 24, 2010 from http://www.unglobalcompact.org/docs /news_events/8.1/GCPaper_ActionPlan_0109.pdf

Griskevicius, V., Tybur, J.M. \& Van de Bergh. (2010). Going green to be seen: Status,reputation, and conspicuous conservation. Journal of Personality and Social Psychology, 98(3),394-404.

Guillory, R.M. \& Wolverton, M. (2008). It's about family: Native American student persistence in higher education. The Journal of Higher Education, 79(1), 58-87.

Hanson, R. D. (2001). Half lives of Reagan's Indian policy: Marketing nuclear waste to American Indians. American Indian Culture and Research Journal, 25(1), 21-44.

Harvard, N. (1996). Student attitudes to studying A-level sciences. Public Understanding of Science, 5, 321-330.

Hodge, F.S. (2012). No meaningful apology for American Indian unethical research abuses. Ethics \& Behavior, 22(6), 431-444.

Hofstede, G. (1981). Culture and organizations. International Studies of Mankind and Organizations, 10(4), 15-41.

Hofstede, G. (2001). Culture's consequences: Comparing values, behaviors, institutions, and organizations across nations ( $2^{\text {nd }}$ ed.). Thousand Oaks, California: Sage Publications, Inc. 
Hollow, W.B., Patterson, D.G., Olsen, P.M., \& Baldwin, L.M. (2004). American Indians and Alaska Natives: How do they find their path to medical school? (Working Paper \#86).

Huntington, H.P. (2000). Using traditional ecological knowledge in science: Methods and applications. Ecological Applications, 10(5), 1270-1274.

Huntingon, H.P. (2002). Can traditional ecological knowledge and wilderness benefit one another? USDA Forest Service Proceedings, RMRS-P-26. Retrieved January 10, 2010 from http://www.fs.fed.us.proxy.lib.pdx.edu/rm/pubs/rmrs_p026/rmrs_p026_064 _068.pdf.

Hyde, J.S. \& Linn, M.C. (2006). Gender similarities in mathematics and science. Science, 314, 599-600.

Ignatow, G. (2006). Cultural models of nature and society: Reconsidering environmental attitudes and concern. Environment and Behavior, 38 (4), 441-461.

Indian Health Service (IHS) (1997). Trends in Indian Health 1998-1999 (chap 4).

Retrieved November 17, 2010, from http://ihs.gov/publicinfo/publications/ trends98/trends98.asp

Institute for Social Research at the University of Michigan. (1958). The Public Impact of Science in the Mass Media: A report on a nation-wide survey for the National Association of Science Writers. Michigan: Institute for Social Research.

Jackson, S.E., Joshi, A. \& Erhardt, N.L. (2003). Recent research on team and organizational diversity: SWOT analysis and implications. Journal of Management, $29(6), 801-830$. 
James, K. (1993). Enhancing the perceived self-relevance of technology to influence attitudes and information retention. Journal of Applied Behavioral Science, 29(1), 5675.

James, K. (2000). Social psychology: American Indians, science and technology. Social Science Computer Review, 18, 196-213.

James, K. (2001). Science and Native American communities: Legacies of pain, visions of promise. Lincoln and London: University of Nebraska Press.

James, K. (2006). Identity, cultural values, and American Indians' perceptions of science and technology. American Indian Culture and Research Journal, 30(3), 45-58.

James, K. \& Cardador, J. (2007). Cognitions about technology and science: A measure and its relevance to career decisions. Journal of Career Assessment, 15(4), 463-482.

James, K. Chavez, E., Beauvais, F. Edwards, R. \& Oetting, G. (1995). School achievement and dropout among Anglo and Indian females and males: A comparative examination. American Indian Culture and Research Journal, 19(3), 181-206.

James, K., Hiza, M., Hall, D. \& Doppelt, R. (2008). Organizational environmental justice and community sustainability with a Navajo (Dine) case example. In S. Gilliland, D. Steiner, \& D. Skarlicki (Eds.), Research in Social Issues in Management, Volume 6: Justice, morality and social responsibility, (pp. 263290). Greenwich, CT: Information Age Publishing.

James, K., Wolf, W., Lovato, C., Byers, S. (1995). Barriers to workplace advancement experienced by Native Americans. Washington, DC: U.S. Department of Labor, Glass Ceiling Commission. 
Jensen, J.D. \& Hurley, R.J. (2010). Conflicting stories about public scientific controversies: Effects of news convergence and divergence on scientists' credibility. Public Understanding of Science, 1-16, Retrieved December 8, 2011 from http://pus.sagepub.com/content/early/2010/11/16/0963662510387759.

Johnson, J.T. \& Murton, B. (2007). Re/placing Native science: Indigenous voices in contemporary constructions of nature. Geographical Research, 45(2), 121-129.

Kaiser, F.G. \& Scheuthle, H. (2003). Two challenges to a moral extension of the theory of planned behavior: Moral norms and just world beliefs in conservationism. Personality and Individual Differences, 35, 1033-1048.

Kates, R. (2003). Sustainability science. In Transition to sustainability in the $21^{\text {st }}$ century: The contribution of science and technology. National Academies Press, 140145.

Kerbo, H.R. (1981). College achievement among Native Americans: A research note. Social Forces, 59(4), 1275-1280.

Kluckhohn, F. (1950). Dominant and substitute profiles of cultural orientations: Their significance for the analysis of social stratification. Social Forces, 28(4), 376-393.

Kluckhohn, F.R. \& Strodtbeck, F.L. (1961). Variations in value orientations. Row, Peterson and Company: Evanston, Illinois

Kronisk, J.A., Judd, C.M. \& Wittenbrink, B. (2005). The measurement of attitudes. In D. Albarracín, B. T. Johnson, \& M. P. Zanna (Eds.), The handbook of attitudes and attitude change (pp. 671-706). Erlbaum.

Kuenzi, J. J. (2008). Science, Technology, Engineering, and Mathmatics (STEM) 
Education: Background, Federal Policy, and Legislative Action. USA: CRS Report for Congress.

Kuhn, T.S. (1970). The structure of scientific revolutions. In Foundation of the unity of science, International Encyclopedia of Unified Science, (Vol. I \& II; $2^{\text {nd }}$ ed.). Chicago: University of Chicago Press.

Lauer, M. \& Aswani, S. (2009). Indigenous ecological knowledge as situated practices: Understanding fishers' knowledge in the Western Solomon Islands. American Anthropology, 111(3), 317-329.

Laugksch, R.C. (1999). Scientific literacy: A conceptual overview. Science Education, $84,71-94$.

Lasswell, H.D. (1927). The theory of political propaganda. The American Political Science Review, 21(3), 627-631.

Lee, O. (1999). Equity implications based on the conceptions of science achievement in major reform documents. Review of Educational Research, 69(1), 83-115.

Lemke, J.L. (2001). Articulating communities: Sociocultural perspectives on science education. Journal of Research in Science Teaching, 38(3), 296-316.

Lemke, M., Sen, A., Pahlke, E., Partelow, L., Miller, D., Williams, T., Kastberg, D., Jocelyn, L. (2004). International Outcomes of Learning in Mathematics Literacy and Problem Solving: PISA 2003 Results From the U.S. Perspective. (NCES 2005-003). Washington, DC: U.S. Department of Education, National Center for Education Statistics.

Lewis, D.R. (1995). Native Americans and the Environment. American Indian Quarterly, 
19(3), 423-450. Retrieved November, 4, 2010 from http://www.jstor.org/stable/ 1185599.

Lewis, J.L., Menzies, H., Najera, E.I., \& Page, R.N. (2009). Rethinking trends in minority participation in the sciences. Science Education, 93, 961-977.

Lertzman, D.A. \& Vredenburg, H. (2005). Indigenous peoples, resource extraction and sustainable development: An ethical approach. Journal of Business Ethics, 56, 239254.

Ley, B.L., Jankowski, N., \& Brewer, P.R. (2010). Investigating CSI: Portrayals of DNA testing on a forensic crime show and their potential effects. Public Understanding of Science, 1, 1-17.

Likert, R. (1932). A technique for measurement of attitudes. Archives of Psychology, 140, $1-55$.

Lynch, Sharon (2005). Examining the effects of a highly rated science curriculum unit on diverse students: Results from a planning grant. Journal of research in science teaching, 42(8), p. 912.

Martinez, M. (March 25, 2011). Jesuits pay record \$166.1 million in child abuse case. CNN Belief Blog. Retrieved March 26 ${ }^{\text {th }}, 2011$ from http://religion.blogs.cnn.com/ 2011/03/25/ esuits-pay-record-166-1-million-in-child-abuse-case/.

Matthews, C. M. (2007). Science, Engineering, and Mathematics Education: Status and Issues. USA: CRS Report for Congress. Retrieved April 26, 2011 from http://www.fas.org/sgp/crs/misc/98-871.pdf

Maznevski, M.L., Gomez, C.B., DiStefano, J.J., Noorderhaven, N.G. \& Wu, P. (2002). 
Cultural dimensions at the individual level of analysis: The cultural orientations framework. International Journal of Cross Cultural Management, 2(3), 275-295. McEachan, R.R.C., Conner, M., Taylor, J.T. \& Lawton, R.J. (2011). Prospective prediction of health-related behaviours with the Theory of Planned Bheaviors: A meta-analysis. Health Psychology Review, 5(2), 97-144, DOI:

$10.1080 / 17437199.2010 .521684$.

Miller, J.D. (1983). Scientific literacy: A conceptual and empirical review. Daedalus, $112(2), 29-48$.

Miller, J.D. (1998). The measurement of civic scientific literacy. Public Understanding of Science, 7, 203-223.

Miller, J. D. (2004). Public understanding of, and attitudes toward, scientific research: What we know and what we need to know. Public Understanding of Science, 13, 273294.

Montgomery, D., Miville, M.L., Winterowd, C., Jeffries, B., \& Baysden, M.F. (2000). American Indian college students: An exploration into resiliency factors revealed through personal stories. Cultural Diversity and Ethnic Minority Psychology, 6(4), 387-398.

Morgeson, F.P. \& Dierdorff, E.C. (2010). Work analysis: From techniques to theory. In Zedeck, S., APA Handbook of Industrial and Organizational Psychology, Volume 2 (Ch.1). Washington, D.C.; American Psychological Association Press.

Moss, M., Tibbetts, L., Henly, S.J., Dahlen, B.J., Patchell, B., \& Struthers, R. (2005). Strengthening American Indian nurse scientist training through tradition: Partnering 
with elders. Journal of Cultural Diversity, 12(2), 50-55.

Moss-Racusin, C.A., Dovidio, J.F., Brescoll, V.L., Graham, M.J., \& Handelsman, J. (2012). Science faculty's subtle gender biases favor male students. PNAS, 109(41), 16474-16479.

Murry, A., James, K. \& Drown, D. (in press). From pictures to numbers: Vision mapping and sustainability collaboration between Native American community members and mainstream scientists. American Indian Culture and Research Journal.

National Science Board. (2009). Building a sustainable energy future. National Science Foundation: Washington D.C. Retrieved April 25, 2010 from http://www.nsf.gov/pubs/2009/nsb0955/nsb0955.pdf.

National Science Board. 2012. Science and Engineering Indicators 2012 (ch.7). Arlington VA: National Science Foundation (NSB 12-01). Retrieved September, $8^{\text {th }}$, 2012 from http://www.nsf.gov/statistics/seind12/c8/c8i.htm.

National Science Foundation (NSF). (2009). Table 20: Doctorate recipients, by citizenship, racelethnicity, and subfield of study: 2009. Retrieved December 13, 2011, from http://www.nsf.gov/statistics/nsf11306/appendix/pdf/tab20.pdf

National Science Foundation (NSF). (2011). Women, minorities, and persons with disabilities in science and engineering: 2011. Division of Science Resources Statistics; Washington D.C.

Ogunwale, S.U. (2002). The American Indian and Alaskan Native population: 2000:

Census 2000 Brief. Retrieved May 8, 2006, from http://www.census.gov/ prod/2002pubs/c2kbr01-15.pdf 
Ogunwale, S.U. (2006). We the people: American Indians and Alaska Native in the United States. Census 2000 Special Reports. Retrieved on June, 2006 from http://www.census.gov/prod/2006pubs/censr-28.pdf.

Osborne, J., Simon, S., \& Collins, S. (2003). Attitudes towards science: A review of the literature and its implications. International Journal of Science Education, 25(9), 1049-1079.

Osgood, C. E., Suci, G. J., \& Tannenbaum, P. H. (1957). The measurement of meaning. Urbana: University of Illinois Press.

Pan, P. (2006). Integrating diversity and cultural education into literacy. Journal of Language and Literacy Education [On-line], 2 (1), 19-31.

Papanastasiou, C. \& Papanastasiou, E.C. (2004). Major influences on attitudes toward science. Educational Research and Evaluation, 10(3), 239-257.

Pardo, R. \& Calvo, F. (2002). Attitudes towards science among the European public: A methodological analysis. Public Understanding of Science, 11, 155-195.

Pardo, R. \& Calvo, F. (2004). Cognitive dimension of public perceptions of science: Methodological issues. Public Understanding of Science, 13, 203-227.

Park, L.E., Young, A.F., Troisi, J.D. \& Pinkus, R.T. (2011). Effects of everyday romantic goal pursuit on women's attitudes toward math and science. Personal and Social Psychology Bulletin, 37(9), 1259-1273.

Peat, F. D. (2002). Blackfoot physics: An exploration of the Native American universe. Boston, MA: Red Wheel/Weiser, LLC.

Poliakoff, E. \& Webb, T.L. (2007). What factors predict scientists' intentions to 
participate in public engagement of science activities? Science Communication, 29(2), $242-263$.

Prislin, R., \& Wood, W. (2005). Social influence: The role of social consensus in attitudes and attitude change. In D. Albarracín, B. T. Johnson, \& M. P. Zanna (Eds.), The handbook of attitudes and attitude change (pp. 671-706). Erlbaum.

Ribot, T. (1906). The scientific imagination. (Albert, H.N., Trans.). Chicago, IL: Open Court Publishing.

Semken, S.C. \& Morgan, F. (1997). Navajo pedagogy and earth systems. Journal of Geoscience Education, 45, 109-112.

Seymour, E. (2000). Tracking the processes of change in US undergraduate education in science, mathematics, engineering, and technology. Science Education, 86(1), 79-105.

Shen, B. S. (1975). Science literacy: Public understanding of science is becoming vitally needed in developing and industrialized countries alike. American Scientist, 63(3), 265-268.

Sherif, M. (1936). The psychology of social norms. Oxford, England: Harper.

Simon, R.M. (2010). Gender differences in knowledge and attitude towards biotechnology. Public Understanding of Science, 19(6), 642-653.

Sommers, D., \& Franklin, J. C. (2012). Overview of projections to 2020. Monthly Labor Review Online, 135(1), 3-20. Retrieved from http://www.bls.gov/opub/mlr/2012/01/.

Stocking, S.H. \& Holstein, L.W. (2009). Manufacturing doubt: Journalists' roles and the construction of ignorance in a scientific controversy. Public Understanding of Science, 18(1), 23-42. 
Sturgis, P. \& Allum, N. (2004). Science in society: Re-evaluating the deficit model of public attitudes. Public Understanding of Science, 13, 55-74.

The Task Force on Women, Minorities, and the Handicapped in Science and Technology. (1989). Changing American: The New Face of Science and Engineering. USA:

Public Law 99-383.

Tabachnick, B.G. \& Fidell, L.S. (2007). Using multivariate statistics $\left(5^{\text {th }}\right.$ ed.). Boston: Allyn \& Bacon.

Tajfel, H. (1978). Differentiation between social groups: Studies in the social psychology of intergroup relations. Academic Press: Oxford.

Tajfel, H. (1982). Social psychology of intergroup relations. Annual Review of Psychology, 33, 1-39.

Tajfel, H. \& Turner, J.C. (1979). Differentiation between social groups: Studies in the social psychology of intergroup relations. Academic Press: London.

Thorton, R. (1987). American Indian holocaust and survival: A population history since 1492. Vol. 186. University of Oklahoma Press: Norman.

Thurstone, L. L., \& Chave, E. J. (1929). The measurement of attitude: A psychophysical method and some experiments with a scale for measuring attitude toward the church. Chicago: University of Chicago Press.

Triandis, H.C., Malpass, R.S. \& Davidson, A.R. (1973). Psychology and culture. In Mussen, P.H. \& Rosenzweig, M.R. (Eds.), Annual Review of Psychology, 24, 355378. Palo Alto: Annual Reviews.

Triandis, H.C., Vassiliou, V. (1972). A comparative analysis of subjective culture. In 
Triandis, H.C., Vassiliou, V., Vassiliou, G., Tanaka, Y., \& Shanmugam, A.V. (Eds.). The analysis of subjective culture. New York: John Wiley \& Sons.

United Nations. (1987). Report of the world commission of environment and development: “Our common future.” General Assembly document A-42-427. Retrieved January 10, 2010 from http:/www.undemocracy.com/A-42-427.pdf. United Nations. (1992). Annex I: Rio declaration on environment and development. Retrieved April 20, 2010 from http://www.un.org/documents/ga/conf151/aconf151261annex1.htm.

United Nations. (1997). UN conference on environment and development (1992). Retrieved April 25, 2010 from http://www.un.org/geninfo/bp/enviro.html U.S. Department of Education. (2006). Answering the challenge of a changing world: Strengthening education for the $21^{\text {st }}$ century. Office of the Secretary; Washington D.C.

Ussher, J.M. (1999). Feminist approaches to qualitative health research. In Murray, M. \& Chamerlain, K. (Eds.). Qualitative health psychology: Theories and methods. Thousand Oaks, CA: Sage.

Van Eijck, M. \& Roth, W. (2007). Keeping the local local: Recalibrating the status of science and traditional ecological knowledge (TEK) in education. Science Education, $91,926-947$.

Walters, K.L., Simoni, J.M. \& Evans-Campbell, T. (2002). Substance use among American Indians and Alaska Natives: Incorporating culture in an "indigenist" stresscoping paradigm. Public Health Reports, 117(3), 104-114. 
Whitbeck, L.B., Adams, G.W., Hoyt, D.R. \& Chen, X. (2004). Conceptualizing and measuring historical trauma among American Indian people. American Journal of Community Psychology, 33(3/4), 119-130.

Whiteshell, N.R., Mitchell, C.M., Spicer, P., \& The Voices of Indian Teens Project Team. (2009). A longitudinal study of self-esteem, cultural identity, and academic success among American Indian adolescents. Cultural Diversity and Ethnic Minority Psychology, 15(1), 38-50.

World's Scientific Academies (2000). Transition to sustainability in the $21^{\text {st }}$ century: The contribution of science and technology. Retrieved April, 25, 2010 from http://www.interacademies.net/?id=3568

Xiao, C. (2011). Public attitudes toward science and technology and concern for the environment: Testing a model of indirect feedback effects. Environment and Behavior, 1-25. Retrieved December 14, 2011 from http://eab.sagepub.com/content/early/2011/07/05/0013916511414875 
Appendix A: Morgan’s Alternative Regression 108 APPENDIX A

In the defense meeting, it was suggested by Dr. Morgan that I split step 3 of my hierarchical regression into two parts, first entering negative attitude toward science (new step 3) and then entering positive attitude toward science (step 4). The expectation was that the unexpected positive beta-weight found for negative attitude toward science in my initial analyses would switch to a negative sign when the shared variance between positive and negative attitudes was not partialled out. I re-ran the hierarchical regression similar to my initial test. Social demographic variables were entered in step 1 and identification with science and cultural values were entered in step 2. However in step 3 only negative attitude toward science (nATS) was included, followed by positive attitude in science (pATS) in step 4. For results from the original analysis, see pages 49-50.

Step 3 (nATS added alone) explained no additional variance (0\%) in intentions to act for Native community sustainability and did not cause a significant change in the Fstatistic $F \Delta(1,36)=.007, p=.94, \mathrm{R}^{2}=.15\left(\operatorname{adj} \mathrm{R}^{2}=-.06\right)$. Consistent with expectations, the beta-weight for nATS did switch from positive, as in the initial analysis $(\beta=.22)$, to negative. However, although the beta-weight was negative its coefficient was negligible $\beta=-.01, p=.94, \mathrm{CI}(90 \%)=-.27-.24$, still failing to support hypothesis $1 \mathrm{~b}$. Negative attitude toward science did not seem to affect intentions to act on sustainable Native community priorities.

In step 4, I entered pATS. This explained an additional $12 \%$ of the variance in intentions to act for Native community sustainability and lead to a significant change in the $F$-statistic beyond the initial analysis, $F \Delta(1,35)=5.89, p=.02, \mathrm{R}^{2}=.28\left(\operatorname{adj} \mathrm{R}^{2}=\right.$ 
Appendix A: Morgan's Alternative Regression 109 .07). This finding increases support for hypothesis 1a. Apparently the additional variance explained by attitudes toward science was completely driven by positive attitude toward science. The relationship between pATS and intentions to act for Native community sustainability was positive, in that for every one unit increase in pATS sustainable action intentions increased by two-fifths of a unit, $\beta=.42, p=.02, \mathrm{CI}(90 \%)=.13-.71$. 
APPENDIX B:

Survey instruments

\section{Demographics}

1. Date of Birth

2. What is your race?

White

African-American

Latino

Asian

Native American

Pacific Islander/Hawaiin

Other

3. What is your education level?

Less than high school

High school graduate

Some college

Associates degree

Bachelor's degree

Master's degree

Doctoral degree

4. What is your field of study?

5. What is your gender?

Male

Female

6. Are you a member of an organized religion?

Yes

No

7. Which religion?

8. What is your occupational affiliation?

9. What is your organization?

10. Are you Native American?

Yes

No

If no, skip to question 19.

11. What is your tribal affiliation?

12. Would you classify yourself as a reservation or Urban Indian?

Reservation-based

Urban-based

13. Are both your parents Native American?

Yes

No

14. Are you enrolled in a federally/state recognized tribe?

Yes

No

15. Do you speak a Native language?

Yes

No

16. Do any of your family members speak a Native language?

Yes

No

17. Do you recognize traditional religion?

Yes

No 
18. Do you attend traditional ceremonies?

Yes

No

\section{Kluckhohn Cultural Values Inventory}

Rated on a 7-point Likert-type scale $(1=$ Strongly disagree -7 Strongly agree $)$

Humanity's innate predispositions

19. Most people are basically evil (evil)

20. Most people do both good and bad things in life (duality)

21. Most people are mainly good hearted (good)

Humanity's relation to nature

22. Technology will eventually allow humans to completely control nature (mastery)

23. People need to find harmony with the environment (harmony)

24. Ultimately, people are at the mercy of nature (mercy)

Time dimensions

25. The most important things in the world occurred in the past (past-orientation)

26. I mainly live my life day to day, not worrying about the past or the future (present-orientation)

27. It is important to me to plan for the future (future-orientation)

Personality

28. Understanding my own true nature is very important to me (Being)

29. It is important that people develop all of their talents (Being-in-becoming)

30. It is important that each person try to do something that makes a mark in society (Doing)

Modality of relationships (relationships to others)

31. Honoring family ties and obligations is very important (Lineal)

32. Keeping on good terms with people my own age is important to me (Collateral)

33. I believe in being independent and free of social control (Individualistic)

\section{Cognitions and Beliefs about Technology \& Science (CABATS)}

Rated on a 7-point Likert-type scale ( 1 = Strongly disagree -7 Strongly agree $)$

Identification with Science and Beliefs about Success in Science

Tech and Self

19. People of my age are better at learning new technologies than people of other ages

20. Most of the people who develop new technologies are of my sex

21. My ethnic/racial group is good at developing new technology

22. My gender is the one that most frequently works with advanced technology (*missing)

Success in Science

23. A career in science requires long, difficult and expensive training

24. Careers in science require taking high personal initiative and personal responsibility 
25. New technologies are difficult to master

26. One has to be very aggressive to succeed in science careers

27. Being competitive helps you succeed in mastering and using the technology

28. I would have a lot of responsibility if I chose a career working with advanced technology

29. Working with high technology requires a solid scientific background

Positive Beliefs about Technology and Science

Economic Advantage Composite

34. New technologies provide many economic benefits

35. The economic competitiveness of the United States depends on our ability to use and create new scientific information

36. The United States as a nation needs to both use and create new technologies in order to compete with foreign countries

37. My home community has experienced many benefits as a result of new technology

38. The economy can be greatly improved as a result of technology (*missing)

Human Capabilities Enhancement Composite

39. Science and technology help individuals to learn and grow

40. My life is much better than my parents because of recent advances in science and technology

41. I could really "make a name for myself" by creating a new technology

42. Modern technology has made today's children ignorant (Reverse coded)

43. Science has enhanced the skills of modern youth

44. Modern science is directed toward frivolous uses rather than important ones (Reverse coded)

45. Science has made modern youth better individuals

46. Technology is wasted in making toys and games (Reverse-coded)

Prestige composite

30. I admire people who work in science

31. People who work with advanced technology are independent

32. I believe that the people who control science today generally have values similar to mine

33. One has to be good with science to have a successful career

34. Independence is a job characteristic of positions involving working with advanced technologies

35. Independence is a job characteristic of positions involving working with advanced technologies

36. Independence is a job characteristic of positions working with advanced technology (*missing)

Negative Beliefs about Technology and Science

Social Damage Dimension Composite

47. Modern science has led to a decline in community unity

48. Introduction of new technology has harmed my home country

49. New machines generally eliminate more jobs than they create

50. Technology is often used without thought as to who it might hurt

51. The opportunity to interact with other people is greatly reduced in scientific professions

52. Respect for people is reduced by new technology

53. Jobs for people are reduced by the use of new machinery (*missing)

Environmental Damage Composite

54. Modern science is the major cause of damage to the physical environment

55. Much of modern science scares me

56. Science is leading us toward disaster

57. New technology is responsible for many of the world's problems 


\section{Appendix B: Survey Instruments 113}

58. I am frightened by modern technologies

Traditionalism composite

59. Modern science makes it difficult to maintain traditions

60. Because of changes in technology, most people today feel little connection with the past

61. People generally get less satisfaction out of their work today than in the past because of changes in technology

62. Some things should be done the old-fashioned way

63. Science makes for a more functional, but a less beautiful, world

64. The cost of new products usually outweigh the gains from them

65. I think everyone would be better off with less science

\section{Native Climate Action \& Research Priorities (NCARP)}

Rated on a 7-point Likert-type scale $(1=$ Not important at all -7 Very important $)$

\section{Action}

37. Create local visions for sustainable communities and sustainable economies

38. Better land use policies and planning by Native communities

39. Link human physical health to community environmental sustainability

40. Create skills and supports for systematic environmental assessments

41. Train grassroots community members in understanding approaches and implications of scientific research

42. Develop approaches to conflict resolution and collaboration between scientists and community members

43. Develop approaches to conflict resolution and collaboration between scientists and government regulators

44. Develop approaches to conflict resolution and collaboration between community members and government regulators

45. Better funding for sustainability planning and action

46. Address needs and problems from population growth

47. Promote subsistence life-styles

48. Promote more local production of goods and materials

49. More local control of commercial and recreational activities in region

50. Address problems created by large-scale resource extraction

51. Develop planning skills among community leaders and community members

52. Complete community-sustainability needs assessments

53. Preserve traditional ecological knowledge and values

54. More and better collaboration between and among local communities

55. Get non-Native governments and organizations to better support Native community goals

56. Develop sustainable technologies for meeting community goals and needs (e.g. better energy availability)

\section{Research}

57. Research and document local/traditional environmental knowledge

58. Better monitoring of changes in Native/wild plants and animals

59. Study approaches to getting the scientific community to acknowledge value of traditional (ecological and other) knowledge 


\section{Appendix B: Survey Instruments 114}

60. Increase documentation of current status of, and change-trends in, local resources (e.g. water quality)

61. Increase tracking of effects of human actions on environmental changes

62. Determine influence of technical/structural features on other aspects of the regional environment

63. Document effects of environmental change on human economic and food production

64. Increase study of presence and impacts of invasive species (that is, non-native insects, plants, animals)

65. Study impacts of environmental change on individual and community health

66. Study possible climate-change impacts on disease spread (e.g. viruses carried by insects and animals)

67. Examine how extreme weather events affect communities and how communities can cope w/ them

68. Study specific strategies and techniques for improving/sustaining environmental qualitiy in communities

69. Study ways of better communicating scientific knowledge about environmental systems to local populations

70. Research influences on individual and community behavior toward environment

71. Test approaches to adapting to global warming

72. Study effects of regional environmental change on community spiritual practices and beliefs 